\title{
Update on the Mechanism of Action of Aripiprazole: Translational Insights into Antipsychotic Strategies Beyond Dopamine Receptor Antagonism
}

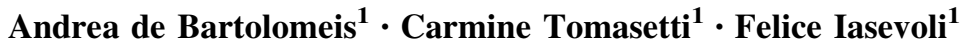

Published online: 7 September 2015

(c) The Author(s) 2015. This article is published with open access at Springerlink.com

\begin{abstract}
Dopamine partial agonism and functional selectivity have been innovative strategies in the pharmacological treatment of schizophrenia and mood disorders and have shifted the concept of dopamine modulation beyond the established approach of dopamine D2 receptor (D2R) antagonism. Despite the fact that aripiprazole was introduced in therapy more than 12 years ago, many questions are still unresolved regarding the complexity of the effects of this agent on signal transduction and intracellular pathways, in part linked to its pleiotropic receptor profile. The complexity of the mechanism of action has progressively shifted the conceptualization of this agent from partial agonism to functional selectivity. From the induction of early genes to modulation of scaffolding proteins and activation of transcription factors, aripiprazole has been shown to affect multiple cellular pathways and several cortical and subcortical neurotransmitter circuitries. Growing evidence shows that, beyond the consequences of D2R occupancy, aripiprazole has a unique neurobiology among available antipsychotics. The effect of chronic administration of aripiprazole on D2R affinity state and number has been especially highlighted, with relevant translational implications for long-term treatment of psychosis. The hypothesized effects of aripiprazole on cellprotective mechanisms and neurite growth, as well as the differential effects on intracellular pathways [i.e. extracellular signal-regulated kinase (ERK)] compared with full D2R antagonists, suggest further exploration of these targets by
\end{abstract}

Andrea de Bartolomeis

adebarto@unina.it

1 Unit of Treatment Resistant Psychosis, Laboratory of Molecular and Translational Psychiatry, Department of Neuroscience, University School of Medicine of Napoli "Federico II", Via Pansini, 5, Edificio n.18, 3rd floor, 80131 Naples, Italy novel and future biased ligand compounds. This review aims to recapitulate the main neurobiological effects of aripiprazole and discuss the potential implications for upcoming improvements in schizophrenia therapy based on dopamine modulation beyond $\mathrm{D} 2 \mathrm{R}$ antagonism.

\section{Key Points}

The atypical antipsychotic aripiprazole has a unique pharmacological profile that provides 'adaptive' pharmacological activity.

Depending on endogenous dopamine levels and signaling status, aripiprazole may act as a full antagonist, a moderate antagonist, or a partial agonist at dopamine D2 receptors (D2Rs), consistent with purported biased ligand pharmacology.

The efficacy of aripiprazole can be mainly attributed to this combination of partial agonism/antagonism at D2Rs and serotonin 5-HT1A receptors, together with antagonism at serotonin 5-HT2A receptors.

However, the receptor profile of the compound is much more complex, and animal models have shown that aripiprazole affects multiple cellular pathways and several cortical and subcortical neurotransmitter circuitries and has an impact on gene expression distinct from other antipsychotics.

Based on the pharmacological and functional characteristics of aripiprazole, a number of new dopaminergic biased ligands are emerging as potential candidates for the treatment of psychosis, potentially improving the 'dopamine modulation' features of the prototypical compound. 


\section{Introduction}

More than 40 years since its first enunciation, the dopamine dysregulation hypothesis of schizophrenia is still considered pivotal for the pathophysiology of the disorder, even if preclinical and clinical research has emphasized the contribution of signaling of other neurotransmitters, primarily the glutamatergic and the serotonergic neurotransmitters [1]. In its simplest form, the dopaminergic hypothesis states that an increase in dopamine release in the striatum (possibly as a final consequence of multiple receptor aberrant interactions) is associated with a reduced dopaminergic tone in the dorsal prefrontal cortex [2]. This mechanistic interpretation is probably too reductionist, particularly considering the complexity of the molecular neurobiology of schizophrenia, which has been recently conceptualized as a disorder of synaptic plasticity [3-5] and of aberrant connectomics [6]; however, dopamine aberrant function represents a major landmark for schizophrenia, both for pathophysiology and for pharmacological treatment.

Multiple lines of evidence, from preclinical models to in vivo neuroimaging studies in humans, demonstrate an aberrant release of dopamine in the striatum of schizophrenia patients [7]. In this regard, dynamic studies measuring the binding of ${ }^{11} \mathrm{C}$-raclopride to striatal dopamine D2 receptors (D2Rs) and dopamine D3 receptors (D3Rs) in schizophrenia patients and in normal controls after an acute amphetamine challenge have robustly demonstrated that schizophrenia is associated with higher dopamine release in the striatum, and that this aberrant release may correlate with positive symptoms [8].

In the context of the dopamine hypothesis, the complexity of dopamine receptor function deserves special emphasis, considering that, until the introduction of aripiprazole, all available antipsychotics were characterized by D2R blockade (albeit to different degrees), and compounds devoid of D2R blockade were not found to have an efficacious antipsychotic action [9]. Aripiprazole has changed this view of antipsychotic action on dopamine signaling, introducing for the first time in the treatment of psychosis a clinically relevant mechanism based on D2R occupancy without D2R blockade. Beyond its peculiar action on D2Rs, preclinical and in vivo studies in humans have demonstrated the differential effects of aripiprazole on dopamine signaling and on multiple transcriptional effectors compared with the action of antipsychotics with full antagonist action at D2Rs. These effects range from the selective induction of early genes to the modulation of distinct scaffolding proteins and transcription factors and imply that the compound targets multiple cellular pathways and affects several neurobiological functions in different forms from full D2R antagonist antipsychotic agents. Furthermore, these effects could be of relevant interest in the onset of secondary antipsychotic treatment resistance, i.e. the onset of treatment resistance after a successful response to an antipsychotic drug. The purpose of this review is to provide a depiction and critical appraisal of the molecular pharmacology of aripiprazole and its effects on neurobiology as a mainstay for future studies on novel molecular targets for antipsychotic effect.

For the literature search, we conducted multiple searches using the PubMed database, with no date constraints but limited to English language articles.

The overall strategy can be summarized in three main sections corresponding to the aim of the review. An initial data search was conducted using the key terms 'aripiprazole' AND 'receptor', 'pharmacokinetics', 'D2 receptor', 'partial agonism', 'functional selectivity', 'PET', 'gene', 'dopamine partial agonists', 'rat'. A second search was conducted focusing on the following key words: 'aripiprazole' AND 'immediate early genes', 'transcription factors', 'c-fos', 'Arc', 'Homer', 'Zif'. A third search included 'aripiprazole derivatives', 'quinolinone derivatives' AND 'dopamine partial agonism', 'ergot derivatives' AND 'dopamine partial agonism', 'dopamine partial agonists' AND 'clinical studies', 'dopamine partial agonists' AND 'preclinical studies'.

A final PubMed search was conducted in March 2015 immediately before the latest version of this review, with no restriction except, again, the English language, using the term 'aripiprazole'. The new preclinical articles that fitted the subject of the article were selected and included.

The articles found were initially reviewed by title and abstract then examined for relevance; after irrelevant articles were discarded, the reference lists of selected articles were used to identify additional studies.

\section{Pharmacokinetic Properties of Aripiprazole}

\subsection{Absorption and Distribution}

The mean elimination half-life of aripiprazole is about $75 \mathrm{~h}$ after oral administration and reaches $94 \mathrm{~h}$ for dehydroaripiprazole, its active metabolite. Steady-state concentrations are attained within 14 days of dosing. After tablet administration, peak plasma concentrations are reached within $3-5 \mathrm{~h}$. Tablet bioavailability is $87 \%$, while plasma concentrations are higher for the oral solution formulation $[10,11]$. Administration with food, particularly a high-fat meal, does not affect mean peak plasma concentration $\left(C_{\max }\right)$ or the area under the plasma concentrationtime curve, while it delays mean time at maximum serum concentration $\left(T_{\max }\right)$ by approximately $3 \mathrm{~h}$ for aripiprazole. 
Steady-state volume of distribution is high, indicating extensive extravascular distribution. At therapeutic concentrations, both aripiprazole and dehydroaripiprazole are $99 \%$ bound to serum proteins, mainly albumin [10]. The pharmacokinetics of aripiprazole do not appear to be affected by age, sex, or body weight [12]. A complete saturation of D2Rs has been described for plasma concentrations of aripiprazole exceeding $100-150 \mathrm{ng} / \mathrm{ml}$ in patients [13] and 100-200 $\mathrm{ng} / \mathrm{ml}$ in healthy subjects [14]. Symptom improvement was best in patients with a serum concentration between 150 and $300 \mathrm{ng} / \mathrm{ml}$ [15].

Aripiprazole is also available as an intramuscular injection for rapid tranquilization [16]. After intramuscular injection, median $T_{\max }$ was at $1 \mathrm{~h}$, absolute bioavailability was $100 \%$, mean $C_{\max }$ was on average approximately $19 \%$ higher than the $C_{\max }$ with oral tablets, the area under the plasma concentration-time curve was $90 \%$ higher than with oral tablets in the first $2 \mathrm{~h}$ after injection [16].

Recently, aripiprazole has also been approved in the USA and in Europe in a long-acting injectable (LAI) formulation at a recommended monthly dose of $400 \mathrm{mg}$. After injection, plasma concentration rises gradually to reach maximum plasma concentration after 5-7 days. Mean halflives are approximately 30 days for the $300-\mathrm{mg}$ formulation and 46 days for the 400-mg formulation. Steady-state concentrations are attained after the fourth administration [17].

Results from a 24-week, open-label, parallel-arm pharmacokinetic study in patients with schizophrenia showed that the plasma concentration curve of aripiprazole LAI $400 \mathrm{mg}$ fell within the concentrations detected with oral aripiprazole $10-30 \mathrm{mg} /$ day at steady state. The mean \pm standard deviation (SD) steady-state $C_{\max }$ of aripiprazole LAI $400 \mathrm{mg}(316 \pm 160 \mathrm{ng} / \mathrm{ml})$ was similar to that obtained with oral aripiprazole $20-30 \mathrm{mg} / \mathrm{day}$ (range $393-452 \mathrm{ng} / \mathrm{ml}$ ) and the minimum steady-state concentration $\left(C_{\min }, 212 \pm 113 \mathrm{ng} / \mathrm{ml}\right)$ was similar to steady-state $C_{\min }$ after $15-20 \mathrm{mg} / \mathrm{day}$ of oral aripiprazole [mean $C_{\min } 214 \mathrm{ng} / \mathrm{ml} \quad(n=283 ; \quad$ mean dose $19.8 \pm 8.2 \mathrm{mg} /$ day, range 5-60)] [18].

\subsection{Metabolism and Elimination}

Aripiprazole is mainly metabolized by human cytochrome P450 (CYP) isozymes CYP3A4 and CYP2D6 to dehydroaripiprazole and several other metabolites [19]. In turn, dehydroaripiprazole is metabolized only by CYP3A4 and CYP2D6 into several components, and the derived metabolites are excreted in urine or feces [20]. Due to these metabolic features, co-administration of aripiprazole with CYP3A4 or CYP2D6 inhibitors may potentially affect the compound pharmacokinetics. Co-administration of itraconazole (a CYP3A4 inhibitor) and aripiprazole in
Japanese subjects was found to reduce the systemic clearance of the antipsychotic by 30 and $50 \%$ in CYP2D6 extensive and intermediate metabolizers, respectively [19]. While genotype has been considered to not affect the activity of CYP3A4 [21], genetic polymorphisms of CYP2D6 have been found to profoundly affect the plasma levels and several other pharmacokinetic parameters of aripiprazole and its active metabolite [20]. Notably, the capacity of poor CYP2D6 metabolizers to metabolize aripiprazole is strongly reduced by this cytochrome, and this may result in about a $60 \%$ higher exposure to the active compound for a given aripiprazole dose compared with that in other subjects [17].

Systemic clearance of aripiprazole has also been found to be strongly reduced by the selective serotonin reuptake inhibitor (SSRI) antidepressants paroxetine (which is a potent CYP2D6 inhibitor) and fluvoxamine (which is a less potent inhibitor of both CYP2D6 and CYP3A4), to an extent that was higher for paroxetine than for fluvoxamine and that was significantly affected by the genotype of the subjects [22]. These observations are relevant since aripiprazole is often used in combination with antidepressants in the treatment of psychotic depression or for depressive symptoms in schizophrenia. Aripiprazole is also frequently co-administered with mood stabilizers for the treatment of bipolar disorder [23]. In one study, it was observed that the concomitant administration of aripiprazole and carbamazepine (an inducer agent of CYP3A4 activity) decreased the values of aripiprazole and dehydroaripiprazole $C_{\max }$ and area under the plasma concentration-time curve [24].

A range of dosage adjustments is recommended in people using the aripiprazole once-monthly LAI formulation. Specifically, reductions in dose are recommended in CYP2D6 poor metabolizers and in patients receiving CYP2D6 and/or CYP3A4 inhibitor agents, while the formulation is not recommended in those receiving CYP3A4inducer agents [17]. A recent 24-week, open-label, phase Ib, parallel-arm, multiple-dose trial in 41 subjects with schizophrenia demonstrated that the once-monthly LAI formulation at doses of 300 and $400 \mathrm{mg}$ provided sustained mean aripiprazole plasma concentrations comparable with the concentration range observed with the corresponding dose of the oral formulation. In contrast, plasma concentrations at a dose of $200 \mathrm{mg}$ were below the therapeutic range [25]. Indeed, a high inter-individual variability in serum concentration/oral dose ratios of aripiprazole has been found in psychiatric patients, ranging through a 27 -fold variance among patients [26]. These inter-individual differences appear not to be determined by dose or sex and may be partially explained by individual differences in CYP2D6 metabolism and/or by hepatic expression of CYP3A4, which can vary up to 100 -fold [27]. 


\section{Ligand-Receptor Interaction Framework Relevant for Aripiprazole Mechanism of Action}

Nowadays, the basic definition of agonist/antagonist drug/ ligand function has been widened by concepts like inverse agonism and biased signaling. These and other drug-target interaction mechanisms are of fundamental importance in the drug discovery field.

A brief description is therefore provided of the binding properties of a drug, to introduce the basic concepts that will be instrumental to the description of the mechanism of action of aripiprazole.

The pharmacological effects deriving from the interaction of a drug with its receptor targets are mainly defined by the unique properties of the drug, including (1) affinity to the target; (2) efficacy or intrinsic activity; (3) selectivity; (4) mode of interaction; (5) residence time [28, 29].

The drug affinity describes the ability of the molecule to bind to its biological target (e.g. receptor, enzyme, transport system). For an agonist (or an antagonist), the numerical representation of the affinity, denoted $K_{\mathrm{A}}$ (or $K_{\mathrm{B}}$ for antagonists), is represented by the reciprocal of the equilibrium dissociation constant $\left(K_{\mathrm{D}}\right)$ of the ligand-receptor complex.

Intrinsic activity defines the ability of the ligand to initiate a response at the molecular, cellular, tissue, or system level and depends on the property of the molecule to occupy and activate (agonist) or block (antagonist) its target. The idea of 'intrinsic activity' of ligand-receptor interaction has led to the classification of ligands into full agonists, partial agonists, neutral antagonists, and inverse agonists [30]. Full agonism refers to the ability of an agonist ligand to produce the full maximal receptor response capability of the target tissue or system. Partial agonism, on the other hand, refers to the production of submaximal amplitude of the biological response [29]. Indeed, a partial agonist is generally predicted to cause agonism at low doses in systems with no other agonist present, while in the presence of a full agonist it is generally expected to act as a competitive antagonist, since it competes with the full agonist for receptor occupancy. Nonetheless, a partial agonist drug with high intrinsic activity may cause the additional activation of receptors, due to receptor sparing, even in the presence of high levels of the endogenous agonist. Moreover, very low intrinsic activity compounds are predicted to not produce threshold response levels but to simply occupy the receptor, resulting in a final antagonist effect [29]. An antagonist is a ligand that has affinity but no intrinsic activity for its cognate receptor, and binding will disrupt the interaction and attenuate the biological effect of an agonist. Antagonists can be competitive and non-competitive, reversible and irreversible, depending on the type of molecular binding to the receptor and competition with the receptor's endogenous ligand. Finally, ligands showing negative intrinsic activity have been termed inverse agonists. These compounds can have effects similar to antagonists depending on the activity state of the receptor [31].

However, the picture is made more complex by a number of additional pharmacological properties that should also be taken into account. The observed potency of a drug (i.e. the biological effect that an external ligand will produce in a system) is a complex function of its affinity and intrinsic activity and is proportional to their values. Therefore, a high-potency drug can show high affinity or high intrinsic activity properties, or both, which also is considered to depend on the sensitivity of the system. In low-sensitivity tissues, drugs that show high potency due to their high intrinsic activity profile will produce more robust effects, while agonists with high potency secondary to a high affinity profile will behave as partial agonists or antagonists. Another primary molecular feature of a drug is its selectivity, which directly depends on the concentration of the molecule with a given affinity and intrinsic activity that causes effects only in the specific targeted system. Moreover, the mode of interaction of the ligand is represented by its capacity to bind the site of the endogenous ligand (orthosteric interaction) or to bind its own site on the receptor, causing a change in the conformation and therefore in the activity of the receptor (allosteric interaction). Finally, the residence time gives a measure of the target kinetics coverage, which depends both on the in vivo pharmacokinetics of the compound and on the receptor dissociation rate.

The concepts of agonism, antagonism, and, more recently inverse agonism, have been regarded as the backbone of ligand-receptor interaction, and those properties of a molecule were classically considered to affect to the same extent all the second messenger cascades depending on the receptor or system impacted by the ligand taken into consideration. Intrinsic activity has been viewed as a system-independent parameter, implicating that a full agonist will have constantly exerted the full receptor response, irrespective of the tissue and the conditions in which the receptor would have been expressed. Also, this theorization implied that a full agonist would have activated all signaling pathways operated by its cognate receptor, and an antagonist would have blocked all downstream signaling pathways coupled to the receptor antagonized [30].

Recently, these concepts have been revised by the introduction of the novel concept of 'functional selectivity', which postulates that a drug may not easily be classified as an agonist or antagonist, but may produce a mix of 
the classic effects through activation or inhibition of only one or a limited number of signal transduction pathways coupled to the target receptor $[32,33]$. This effect may stem from the induction of unique, ligand-specific conformations of the target receptor complex that result in differential activation of one or multiple signal transduction pathways downstream of the receptor [30, 34, 35]. These molecular effects may depend on the signaling machinery associated with the receptor, and thereby on the type and localization of the cells expressing the target receptor [30]. Among the several subfamilies of receptors, functional selectivity appears to apply to $G$ protein-coupled receptors (GPCRs), among which are also included those of the D2R-like subtype [30], the main target receptor of antipsychotic compounds.

\section{Pharmacodynamic Properties of Aripiprazole}

\subsection{Receptor Profile}

Table 1 lists the affinity of aripiprazole for a wide range of relevant central nervous system receptors. Among dopamine receptors, aripiprazole has high affinity for the D2R and D3R subtypes, while affinity is limited or negligible for dopamine D1 (D1R), D4 (D4R), and D5 (D5R) receptor subtypes [36]. Among serotonergic receptors, aripiprazole has very high and high affinity at 5-HT1A (5-HT1AR), 5-HT2A (5-HT2AR), 5-HT2B (5-HT2BR), and 5-HT7 (5HT7R) receptors [36]. Affinity is moderate at 5-HT1D (5HT1DR) and 5-HT2C (5-HT2CR) receptors, limited at 5-HT1B (5-HT1BR), 5-HT3 (5-HT3R), and 5-HT6 (5HT6R) receptors, and negligible at 5-HT1E (5-HT1ER) and 5-HT5 (5-HT5R) receptors and at serotonin transporters (Table 1).

Among other neurotransmitter systems, aripiprazole has moderate affinity at adrenergic $\alpha 1 \mathrm{~A}, \alpha 1 \mathrm{~B}, \alpha 2 \mathrm{~A}$, and $\alpha 2 \mathrm{C}$ receptors and at histaminergic H1 (H1R) receptors (Table 1). The compound also has limited affinity at $\alpha 2 \mathrm{~B}$, $\beta 1, \beta 2$, and $\mathrm{H} 3$ receptors. Affinity is negligible at cholinergic, gamma-aminobutyric acid (GABA)ergic, glutamatergic, and opioidergic receptors [36].

\subsection{Molecular Action of Aripiprazole on Dopamine D2 Receptors (D2Rs): From Partial Agonism to Functional Selectivity}

Aripiprazole has high affinity for D2Rs [37], with one of the highest affinities at this receptor for an antipsychotic drug $(\mathrm{Ki}=0.34 \mathrm{nM})$. Despite a low incidence of acute extrapyramidal side effects (EPS), the compound at therapeutic doses has been demonstrated to occupy up to $95 \%$ of D2Rs in the striatum $[14,38]$, a value significantly over the threshold necessary for antipsychotics to trigger EPS. On the other hand, the drug stimulates D2Rs only in a submaximal fraction of the stimulation elicited by the endogenous ligand, i.e. dopamine. Therefore, the intrinsic activity of aripiprazole at D2Rs may appear to be lower than that of dopamine.

In D2R stably transfected MES-23.5 cells, quinpirole (a D2R/D3R agonist) increased D2R-mediated outward $\mathrm{K}^{+}$ currents, while aripiprazole had no effects [36]. Notably, in this system, when D3Rs rather than D2Rs were transfected, aripiprazole behaved as a full agonist, matching the biological effects of quinpirole [36]. In D2R transfected Chinese hamster ovary $(\mathrm{CHO})$ cells, aripiprazole on its own had no effects on guanosine 5'-O-[gammathio]triphosphate $(\mathrm{GTP} \gamma \mathrm{S}$ ) binding (a measure of the activation of D2R-mediated downstream signaling) and blocked the effects of either dopamine or quinpirole [36]. Nonetheless, stable expression of high levels of D2 long receptors (D2LR) in CHO and human embryonic kidney (HEK) cells caused aripiprazole to behave as a full agonist with moderate intrinsic activity [36, 37]. In another set of experiments in $\mathrm{CHO}$ cells, aripiprazole acted as an antagonist in cells expressing low levels of human D2LRs ( $\mathrm{hD} 2 \mathrm{LR}$ ), as a low intrinsic activity agonist in cells expressing low levels of human D2 short receptors (hD2SR), as a high intrinsic activity agonist in cells expressing high levels of hD2LRs, and as a full agonist in cells expressing high levels of hD2SRs [39]. Unlike previous reports, aripiprazole apparently acted as a partial agonist in CHO cells expressing human D3Rs [39-41].

The biological activity of aripiprazole has also been tested in hD2LR-CHO transfected cells on three D2Rmediated downstream functional effectors [42]. Aripiprazole displayed approximately $50 \%$ of quinpirole activity to mediate D2R-dependent mitogen-activated protein kinase (MAPK) phosphorylation, and potentiated the D2Rdependent release of arachidonic acid (AA). Intriguingly, the potency of aripiprazole for the potentiation of AA release was significantly higher than that for MAPK phosphorylation, while the relative potency for each of these downstream effectors was comparable for other D2R ligands, including dopamine and quinpirole. Moreover, unlike dopamine, aripiprazole did not mediate significant D2R internalization [42]. These data indicate that aripiprazole behaves as a biased ligand at D2R/D3Rs, alternating partial agonist or antagonist features at these receptors.

The pivotal concept that has been put forward for many years is that aripiprazole, as distinct to other antipsychotics, may have a differential action on D2Rs and may act as a prevalent antagonist when the synaptic concentration of dopamine is elevated or may act as a prevalent D2R partial agonist when the concentrations of 


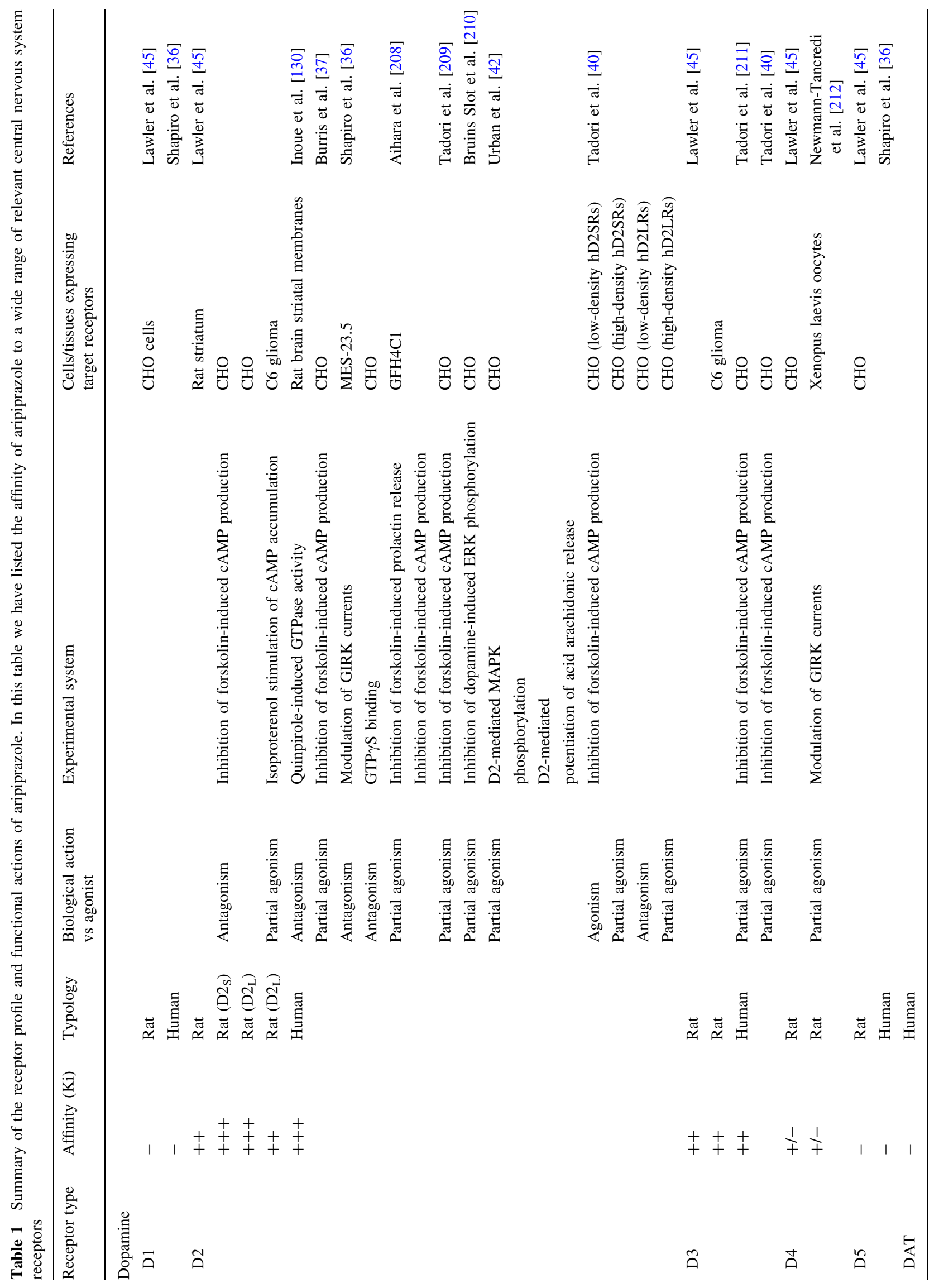




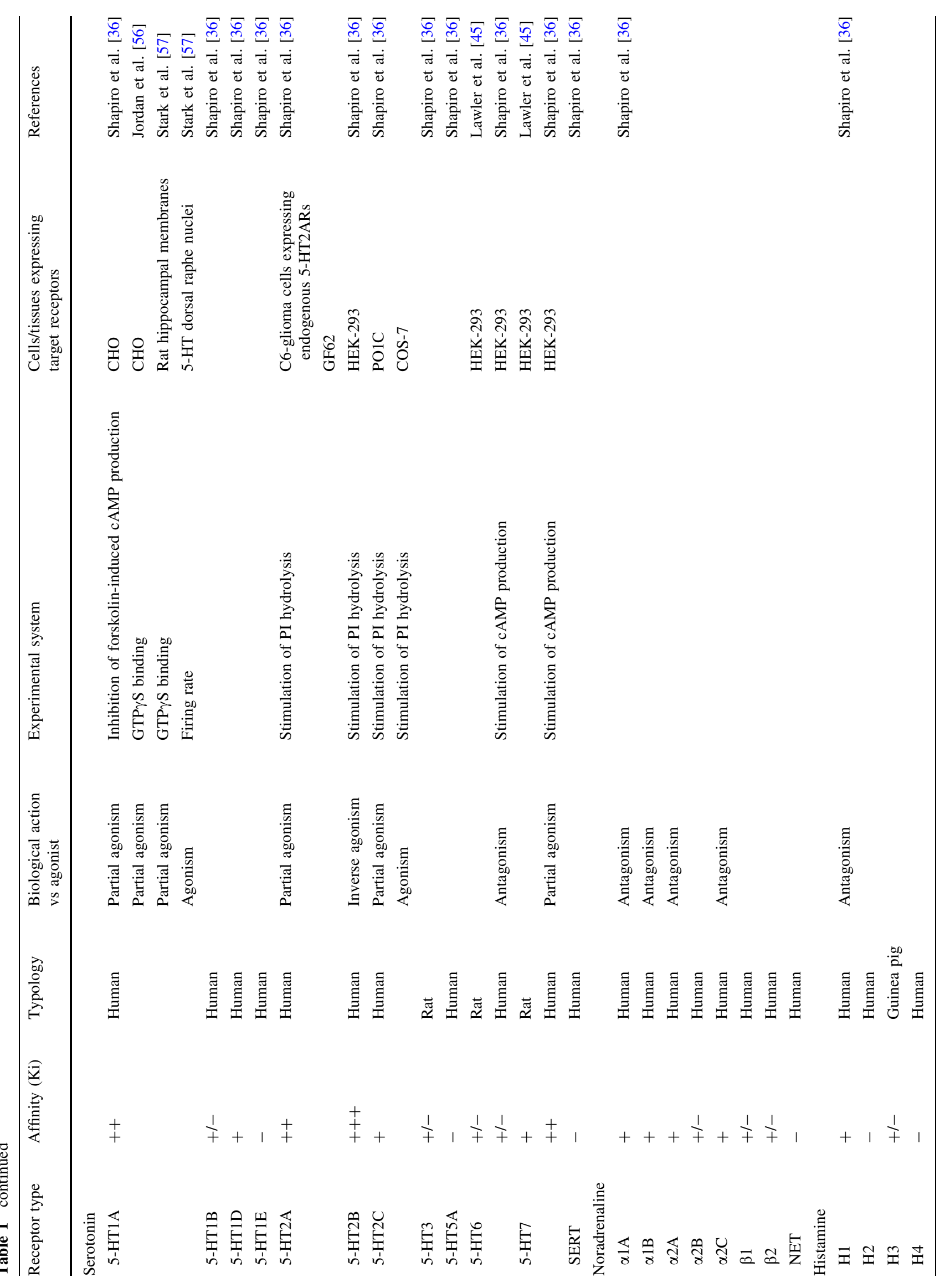




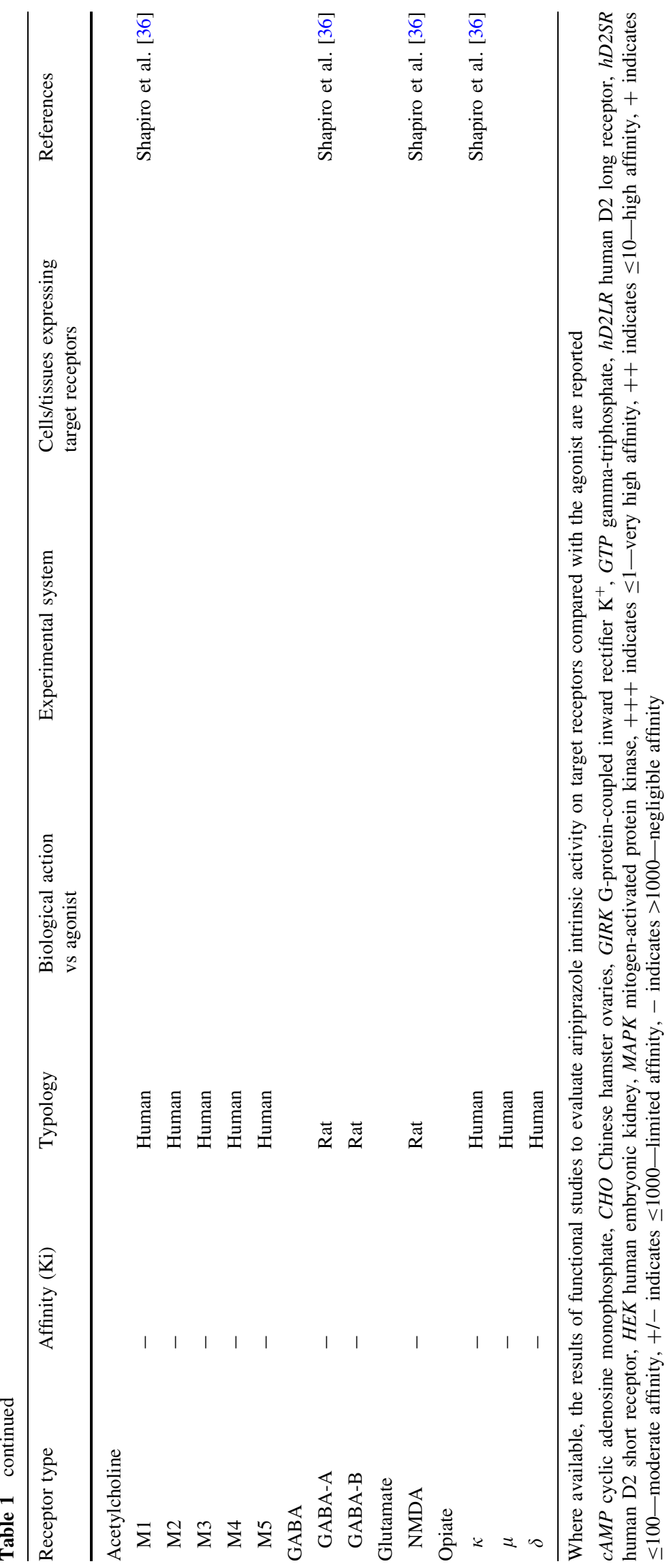

么 Adis 
dopamine are low. It has been proposed that the combination of tight $\mathrm{D} 2 \mathrm{R}$ binding and partial agonism at this receptor may explain the favorable therapeutic/side effect profile of aripiprazole. Specifically, aripiprazole may suppress phasic dopamine release due to burst firing of dopaminergic neurons, which may explain its therapeutic efficacy, while tonic dopamine release may be relatively preserved due to the partial agonist action of the compound [43]. This feature separates aripiprazole from antipsychotics with full antagonist action and tight binding at D2Rs, which suppress both tonic and phasic dopamine release; this may explain the EPS liability of these compounds.

Very recently, this concept has been elegantly addressed considering the properties of aripiprazole at D2R-like autoreceptors by detecting dopamine synthesis changes in rat brain striatal tissue incubated ex vivo. The differential effects of the dopaminergic tone on aripiprazole pharmacodynamic features were studied by comparing a basal condition $\left(2 \mathrm{mM} \mathrm{K} \mathrm{K}^{+}\right.$, low dopaminergic tone $)$and a stimulated condition $\left(15 \mathrm{mM} \mathrm{K}^{+}\right.$, where dopamine release mimics an increased dopaminergic tone). In basal conditions, aripiprazole acted as an agonist at D2R autoreceptors, whereas in high (stimulated) concentrations of dopamine, even at high doses, aripiprazole did not act at D2R autoreceptors but antagonized the activation of D2R by dopaminergic agonists such as quinpirole [44].

However, the observation that aripiprazole elicits multiple D2R-mediated functional effects encompassing the whole range of pharmacological traits has enabled a progressive shift in the conceptualization of the mechanism of action of this drug, strengthening the hypothesis of a functional selective modulation of D2R-dependent specific downstream signaling pathways [45, 46]. It has been reported that supposed partial agonist agents may exert a ligand-dependent modulation of micro-switches relevant to receptor activation and to submaximal coupling to intracellular effectors [47]. Also, these agents may regulate ligand-specific conformations within receptor-specific epitopes, including areas of receptor-G-protein coupling [48]. In an active-state homology model of the D2R-Gai-protein complex, aripiprazole induced different conformations of essential structural motifs, including the extracellular loop regions, the binding pocket, and the intracellular G-proteinbiding domains [49]. These ligand-specific conformational changes have functional consequences. In an oocyte cell expression system, aripiprazole slightly reduced currents through a G-protein-coupled inward rectifier $\mathrm{K}^{+}$(GIRK) channel co-expressed with hD2LRs, while multiple antipsychotics completely abolished these currents [50]. These observations better fit with a model of 'functional selectivity', predicting that a drug can cause multiple functional effects even when interacting with a single receptor isoform [35]. One postulated mechanism for functional selectivity (that may fit well with experimental data on the biological action of aripiprazole) is that the target drug may trigger different conformation changes, compared with the endogenous ligand, when binding to the receptor-G protein complex. Such functional targeting allows for a degree of refined drug effects that could not be reached by merely targeting specific receptor isoforms [35]. The peculiarity of the mechanism of action of aripiprazole at D2Rs is also suggested by the fact that aripiprazole, differently from a canonical D2R agonist and/or partial agonist, does not elicit a contraversive rotation in rats with a unilateral lesion of nigrostriatal pathway induced by 6-OH-dopamine [51].

Moving to clinical use, it should be noted that, compared with partial agonist agents with potential antipsychotic activity, aripiprazole is currently the only one that has succeeded in all the clinical stages needed for drug approval and use in patients, whereas other compounds have failed due to progressive loss of efficacy, as in the case of preclamol (3PPP), or for adverse events, as for OPC-4392, the precursor of aripiprazole [52, 53]. In a behavioral, gene expression and binding experiment, Natesan et al. [54] demonstrated that all partial agonists considered to be potential antipsychotics, such as 3PPP, terguride, OPC-4392, and aripiprazole, occupied striatal D2Rs in a dose-dependent manner, inhibited amphetamineinduced locomotion (AIL) and conditioned avoidance response (CAR), and did not induce motor side effects or hyperprolactinemia, despite D2R occupancy being higher than $80 \%$ [54]. At comparative doses, aripiprazole showed the least rotation in the hypo-dopaminergic model (possibly indicating the least intrinsic activity) and the highest c-Fos expression in the nucleus accumbens [54]. One explanation for the greater clinical efficacy of aripiprazole may rely on its action as a biased ligand compound, rather than a pure partial agonist at dopamine receptors.

In summary, aripiprazole may behave as a functionally selective agent, with its intrinsic activity varying greatly and depending on the experimental paradigm as well as the D2R signaling environment encountered. A schematic model of possible mechanisms explaining the postsynaptic functional selectivity of aripiprazole is presented in Fig. 1.

\subsection{Functional Relevance of Other Receptor Interactions beyond D2Rs}

In multiple in vitro assays, aripiprazole behaved as a partial agonist at 5-HT1ARs [55]. In 5-HT1AR-transfected CHO cells, the compound inhibited forskolin-stimulated cyclic adenosine monophosphate (cAMP) production moderately and less potently than serotonin. In the same cellular model, aripiprazole stimulated binding of GTP $\gamma \mathrm{S}$ to 


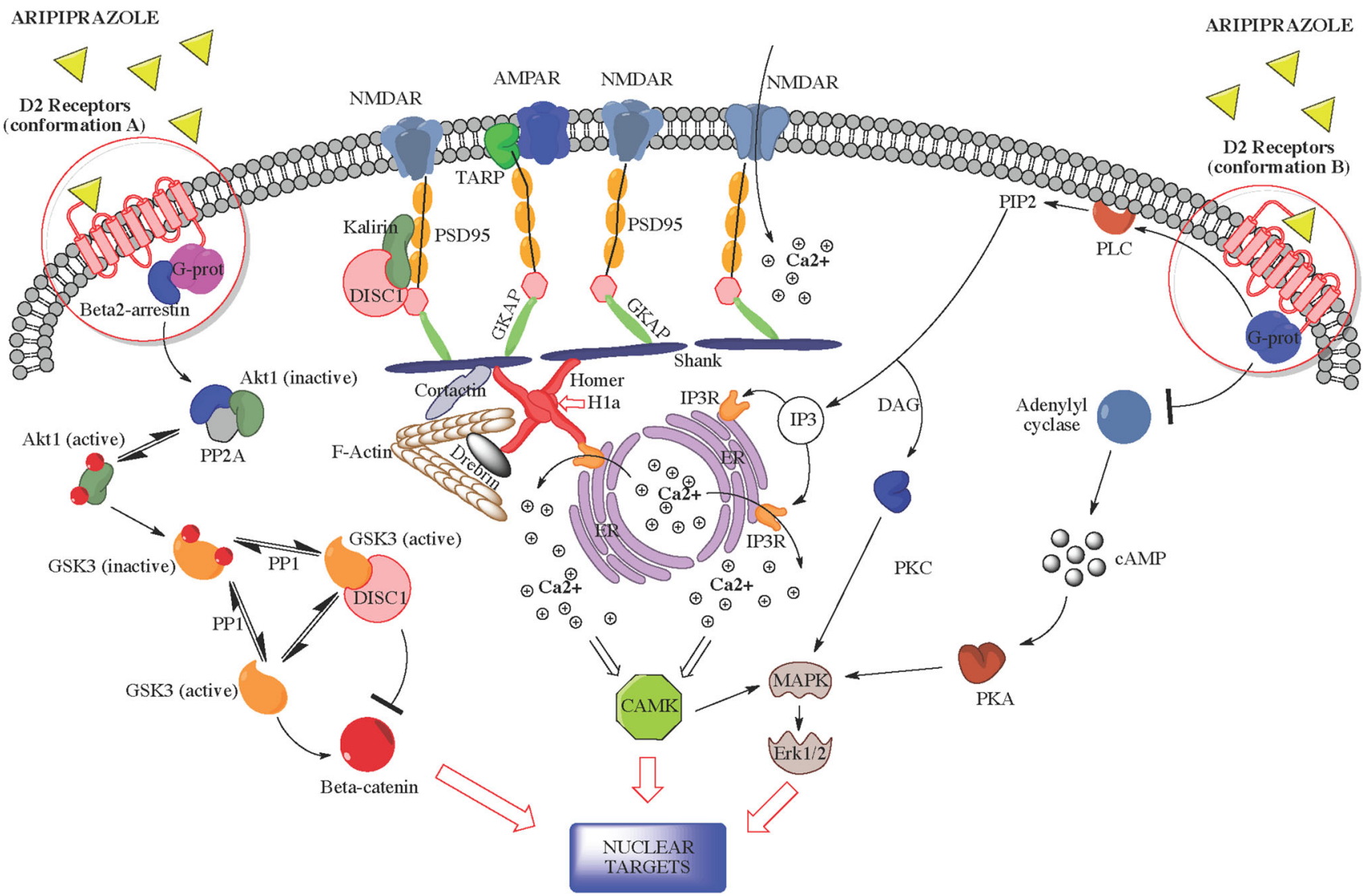

Fig. 1 Postsynaptic functional selectivity of aripiprazole. Aripiprazole is supposed to cause functional multiplicity at dopamine D2 receptors postsynaptic downstream pathways. One mechanism of functional selectivity may be the preferential binding to different conformations of D2 receptors, which have been demonstrated to activate differential transductional pathways according to the neuronal subtypes in which they are expressed. Postsynaptic scaffolding/ adaptors and effectors may be differentially impacted by each dopamine D2 receptor conformation-related pathway selectively activated by aripiprazole. AMPAR $\alpha$-amino-3-hydroxy-5-methyl-4isoxazolepropionic acid glutamate receptor, CAMK calcium-

surface membrane human 5-HT1ARs transfected in the cells [56]. Levels of GTP $\gamma \mathrm{S}$ binding by aripiprazole were inferior to those observed with serotonin, and were completely abolished by a full 5-HT1AR antagonist [56]. Aripiprazole also stimulated GTP $\gamma \mathrm{S}$ binding to serotonin receptors in rat hippocampal membranes, an action that was completely blocked by a 5-HT1AR antagonist [57]. Despite these in vitro assays, where aripiprazole behaved as a partial agonist, the compound exerted full agonistic properties in an electrophysiological study. Indeed, aripiprazole dose dependently reduced the firing rate of serotonin-containing dorsal raphe nuclei, an action that was reversed by a 5-HT1AR antagonist [57]. These data suggest that the inhibition of serotonin neuronal activity by aripiprazole is mediated by its agonist action on calmodulin regulated kinase, $c A M P$ cyclic adenosine monophosphate, $D A G$ diacylglycerol, DISCl disrupted in schizophrenia 1, ER endoplasmic reticulum, Erk extracellular signal-regulated kinase, GKAP guanylate kinase-associated protein, GSK3 glycogen synthase kinase 3, H1a Homer1a immediate-early inducible protein, IP3 inositol 1,4,5trisphosphate, MAPKs mitogen-activated protein kinases, $M E K$ MAPK/Erk kinase, $n M D A R N$-methyl-D-aspartate glutamate receptor, PDE4 phosphodiesterase 4, PIP2 phosphatidylinositol bisphosphate, $P K A$ protein kinase A, $P K C$ protein kinase $\mathrm{C}, P L C$ phospholipase $\mathrm{C}$, $P S D-95$ postsynaptic density protein $95 \mathrm{kD}$, TARP transmembrane AMPA receptors regulating protein or stargazin

somatodendritic 5-HT1AR autoreceptors located onto dorsal raphe serotonergic neurons. The full agonistic activity may be explained by the large 5-HT1AR reserve in these nuclei and may be relevant to the global pharmacological action of aripiprazole. Dorsal raphe serotonergic neurons provide major afferent projections to the frontal cortex. Agonist action on somatodendritic 5-HT1ARs reduces serotonin release in the cortex, which in turn stimulates dopamine release therein [58], an action that may be beneficial for negative and cognitive symptoms of schizophrenia. Notably, impairment in recognition memory induced by repeated phencyclidine administration was ameliorated by aripiprazole, whose beneficial effects were in turn abolished by co-administration of a D1R antagonist and a 5-HT1AR antagonist [59]. Aripiprazole also 
improved social behavior deficits caused by repeated phencyclidine, an effect that was prevented by pretreatment with a 5-HT1AR antagonist [60, 61]. Moreover, aripiprazole appears to inhibit marble-burying behavior, an animal model of obsessive compulsive disorder, via its action on 5-HT1ARs. Low-dose systemic aripiprazole $(<1 \mathrm{mg} / \mathrm{kg})$ also increased extracellular dopamine levels in the cortex $[62,63]$. On the other hand, high-dose systemic aripiprazole $(10-40 \mathrm{mg} / \mathrm{kg})$ reduced dopamine levels [6466]. This biphasic effect may depend on the prevalence of agonistic 5-HT1AR-mediated effects at low doses, and the prevalence of inhibition of mesocortical dopaminergic neurons activity at high doses [65].

From a translational perspective, the action of aripiprazole at 5-HT1ARs has been associated with a potential modulation of cognitive effects $[67,68]$.

Aripiprazole has partial agonist/antagonist activity at 5-HT1ARs. In C6-glioma cells expressing low levels of endogenous 5-HT1ARs, aripiprazole induced phosphatidyl-inositol (PI) hydrolysis only at the highest concentrations and significantly less than did serotonin, while in 5-HT1AR-transfected GF62 cells, expressing high levels of the receptors, aripiprazole still behaved as a partial agonist but with a slightly higher intrinsic activity [36]. The hallucinogen 2,5-dimethoxy-4-iodoamphetamine (DOI) is a 5-HT2A/2CR agonist that increases serotonin levels in the rat medial prefrontal cortex [69]. The effects on serotonin levels were reversed by high, but not low, concentrations of aripiprazole [65], a finding in apparent agreement with a partial agonist activity on 5-HT1ARs. However, in rat P11 cells expressing 5-HT1ARs linked to the PI signaling, the effects of serotonin on this pathway were potently blocked by aripiprazole, as well as by other antipsychotics with known antagonist activity at 5-HT1ARs, including risperidone, clozapine, and haloperidol [57]. A modest 5-HT1AR antagonism was also found in 5-HT1AR stably transfected $\mathrm{CHO}$ cells and in transiently transfected HEK cells, in another set of in vitro experiments [70]. In behavioral assays, aripiprazole inhibited the wet-dog shake responses and ameliorated the disruption in pre-pulse inhibition induced by DOI [71]. These data suggest that aripiprazole may behave as a full 5-HT1AR antagonist in vivo.

Considering the other serotonergic receptors, aripiprazole behaved as an inverse agonist at 5-HT2BRs, as a partial agonist at high intrinsic activity at 5-HT2CRs, as an antagonist at 5-HT6Rs, and as a weak partial agonist at 5-HT7Rs [36]. The effects at 5-HT2CRs strongly depended on the system under consideration. Aripiprazole was a partial agonist at these receptors when expressed in PO1C cells, while it was a weak full agonist in 5-HT2CR stably transfected COS-7 cells [36]. In another study, aripiprazole increased 5-HT2CR-mediated elevation of $\mathrm{Ca}^{2+}$ levels in
$\mathrm{CHO}$ cells, but reduced the increase in $\mathrm{Ca}^{2+}$ levels induced by serotonin [70]. Similar results were also found in 5-HT2CR transiently transfected HEK cells [70]. These data suggest that aripiprazole may behave as a full 5-HT2CR agonist when serotonin tone is low and receptor reserve is high, and as an antagonist in cases of high serotonin tone/low receptor reserve. Agonism at 5-HT2CRs has been considered beneficial to reducing appetite and preventing drug-induced weight gain. According to these considerations, a statistically significant weight increase was found when aripiprazole was combined with high serotonergic antidepressants [72], possibly due to the elevation of serotonin tone by these latter compounds. Intriguingly, the same effect was not observed when aripiprazole was combined with low serotonergic activity antidepressants.

Finally, a relevant translational issue dealing with the complexity of the receptor profile of aripiprazole is the coadministration of this agent with other psychotropic compounds, a drug combination frequently used in clinical practice to address multiple dimensions of severe psychiatric diseases such as schizophrenia and bipolar disorders, or to counteract the onset of antipsychotic-resistant schizophrenia. For instance, the combination of clozapine and aripiprazole may lead to greater D2R antagonism in mesolimbic pathways and, additionally, may combine D2R and D4R antagonism [73].

\subsection{In Vivo Neuroimaging Studies}

The first neuroimaging study on the effects of aripiprazole aimed to investigate striatal D2R/D3R occupancy in 15 normal male human brains by positron emission tomography (PET) with ${ }^{11} \mathrm{C}$-raclopride. Prolonged (i.e. 14 days) administration of aripiprazole caused a dose-dependent increase in the occupancy of D2R/D3Rs, reaching approximately $95 \%$ at the 30-mg dose [14]. Notably, even at the highest dose and with very high levels of D2R occupancy, a low occurrence of EPS was observed in the subjects. According to the full antagonist-based hypothesis, antipsychotic-mediated EPS become apparent when D2R occupancy exceeds $80 \%$ [74, 75]. The relatively low rate of EPS, even with the high aripiprazole-induced D2R occupancy, represents a specific hallmark of the compound, and places aripiprazole in a stand-alone class among antipsychotic compounds. Indeed, low rates or lack of EPS have also been reported with clozapine and quetiapine, a feature that has been attributed to their fast-off kinetics from D2R binding [76]. However, both compounds are known to reach only low-to-intermediate levels of striatal D2R occupancy [74, 77]. The unique profile of high D2R occupancy/low or no acute EPS with aripiprazole may be due to the functional selectivity of the 
compound, as described above, and may suggest the suitability of aripiprazole in patients whose symptoms (i.e. productive ones) need tight D2R blockade with low EPS liability.

An elegant triple labeling PET experiment in schizophrenia or schizoaffective disorder patients has subsequently demonstrated that aripiprazole differentially occupies D2Rs, 5-HT1ARs, and 5-HT2ARs [78]. Specifically, striatal D2R occupancy was high (approximately $85 \%$ ), even at the lowest drug dose investigated (i.e. $10 \mathrm{mg}$ ), and increased dose dependently. Aripiprazole dose and plasma concentration showed a linear correlation with striatal D2R occupancy. Conversely, drug occupancy was lower for 5-HT2ARs and the lowest for 5-HT1ARs in the temporal and frontal cortices, and there was no relationship with aripiprazole dose or plasma concentration.

Nonetheless, the role of extra-striatal brain regions in aripiprazole binding has been considered relevant for a potential 'relative brain region selectivity'. ${ }^{18} \mathrm{~F}$-fallypride is a dopaminergic radioligand that, unlike raclopride, binds both striatal and extra-striatal D2Rs. Using this radioligand in schizophrenia patients taking aripiprazole (dose range 3-40 mg/day) exhibited a slight but higher extra-striatal D2R occupancy compared with the striatal occupancy [79], although no binding difference across brain regions was found in another study with the same radioligand [13]. Notably, previous studies using ${ }^{18} \mathrm{~F}$-fallypride have shown that clozapine in a certain dose range can have higher D2R binding in the temporal cortex compared with the striatum [80], leaving the mechanism behind this observation and its clinical meaning to be clarified. One possible explanation of the slight but significantly higher extra-striatal binding in the temporal cortex compared with the striatum may be the higher concentration of dopamine in the striatum and therefore the higher competition with the radioligand binding to D2Rs. Remarkably, an ex vivo study of synaptic plasticity genes showed a specific pattern of expression of inducible and constitutive postsynaptic density genes in extra-striatal tissues, i.e. the cortex [81]. However, a more recent PET study, using ${ }^{11} \mathrm{C}-((S)-N$-((1-ethyl-2-pyrrolidinyl)methyl)-5-bromo-2,3-dimethoxybenzamide) (FLB 457 ) as the radioligand for extra-striatal $\mathrm{D} 2 \mathrm{Rs}$ and ${ }^{11} \mathrm{C}$ raclopride for striatal D2Rs, failed to support the previous observations on higher extra-striatal D2R occupancy by aripiprazole, and, moreover, showed higher striatal occupancy [82].

Despite providing intriguing data, these studies did not clarify whether and how aripiprazole may affect the presynaptic dopaminergic function in vivo. Recently, by means of a two-session PET study, the presynaptic and postsynaptic effects of a single aripiprazole administration were explored using, respectively, $\mathrm{L}-\beta-{ }^{11} \mathrm{C}-3,4$-dihydroxyphenylalanine (DOPA) and ${ }^{11} \mathrm{C}$-raclopride in 12 healthy subjects [83]. No significant changes in the synthesis capacity of dopamine by aripiprazole were found. This observation sharply contrasted with preclinical studies reporting an increase in dopamine synthesis by the compound [84], a discrepancy most likely depending on the differences in administration, dose and duration of treatment in the different clinical versus preclinical paradigms. However, most relevantly, the authors found significant negative correlations between baseline dopamine synthesis capacity and the percentage changes in dopamine synthesis capacity after the single aripiprazole administration regimen [83]. This observation suggests that aripiprazole increases dopamine synthesis in subjects with low baseline dopamine levels and decreases it in subjects with high baseline levels, again providing strong support for a functionally selective action on dopamine receptors and its translational relevance in dopamine dysfunctional pathophysiology.

\subsection{Effects on the Transcription of Molecules Relevant to the Pathophysiology of Psychosis}

Aripiprazole-mediated changes of the neuronal transcriptome in relevant biological functions have been studied with gene expression analysis. These studies have also found substantial differences in transcriptome changes between aripiprazole and the other antipsychotics, which corroborate the view that aripiprazole impacts distinctive neurobiological pathways compared with traditional antipsychotics. Table 2 summarizes the most relevant studies on aripiprazole-mediated gene expression in the central nervous system.

Aripiprazole has been observed to differentially modulate the expression of genes implicated in dopaminergic signaling in brain areas belonging to mesolimbic versus nigrostriatal dopamine pathways. Indeed, 12-week treatment with an oral dose of aripiprazole $2.25 \mathrm{mg} / \mathrm{kg}$ has been demonstrated to significantly increase messenger RNA (mRNA) expression of D2Rs and decrease tyrosine hydroxylase mRNA expression in the rat ventral tegmental area (VTA), with no effects in the substantia nigra or the nucleus accumbens [85]. Conversely, haloperidol has been found to increase the binding density of D2Rs in the nucleus accumbens and caudate putamen, as well as to decrease dopamine transporter (DAT) binding in these two areas and in the VTA. Olanzapine may increase D2R mRNA in VTA and DAT binding in nucleus accumbens. Therefore, these results suggest that aripiprazole has more selective effects on the mesolimbic dopaminergic pathway than haloperidol and olanzapine [85].

Earlier studies also demonstrated that aripiprazole may significantly reduce D2R gene expression in the rat pituitary, whereas haloperidol increases both D2R and 
Table 2 Effects of aripiprazole on gene expression in the central nervous system. This table summarizes the most relevant studies on aripiprazole-mediated gene expression in the central nervous system

\begin{tabular}{|c|c|c|c|c|c|c|}
\hline Gene & $\begin{array}{l}\text { Levels of } \\
\text { expression }\end{array}$ & Exp paradigm & Strain & Brain region & Method & References \\
\hline \multirow[t]{3}{*}{ DRD2 } & Not affected & $\begin{array}{l}12 \text { or } 100 \mathrm{mg} / \mathrm{kg} \mathrm{PO} \\
21 \text { days }\end{array}$ & Wistar rats & Striatum & Ribonuclease protection assay & Inoue et al. [130] \\
\hline & $\downarrow$ & $\begin{array}{l}24 \mathrm{mg} / \mathrm{kg} \mathrm{PO} \\
21 \text { days }\end{array}$ & Wistar rats & Pituitary & Ribonuclease protection assay & Inoue et al. [86] \\
\hline & & $\begin{array}{l}10 \mathrm{mg} / \mathrm{kg} \mathrm{IP} \\
21 \text { days }\end{array}$ & & & RT-PCR & Luoni et al. [133] \\
\hline \multirow[t]{4}{*}{ Homerla } & $\uparrow$ & $\begin{array}{l}12 \mathrm{mg} / \mathrm{kg} \mathrm{IP} \\
\text { Acute }\end{array}$ & $\mathrm{SD}$ rats & $\mathrm{CP}$ & ISSH & Tomasetti et al. [81] \\
\hline & $\uparrow$ & $30 \mathrm{mg} / \mathrm{kg}$ IP & & $\mathrm{FrC}$ & & \\
\hline & & Acute & & $\begin{array}{l}\text { ACC } \\
\text { Shell of accumbens }\end{array}$ & & \\
\hline & $\uparrow$ & $\begin{array}{l}12 \mathrm{mg} / \mathrm{kg} \mathrm{IP} \\
21 \text { days }\end{array}$ & & $\begin{array}{l}\mathrm{FrC} \\
\text { ACC } \\
\text { Lateral CP }\end{array}$ & & \\
\hline \multirow[t]{3}{*}{ Arc } & $\uparrow$ & $\begin{array}{l}10 \mathrm{mg} / \mathrm{kg} \mathrm{IP} \\
21 \text { days }\end{array}$ & $\mathrm{SD}$ rats & $\begin{array}{l}\text { Hippocampus } \\
\text { PFC } \\
\text { Striatum }\end{array}$ & qRT-PCR & Luoni et al. [133] \\
\hline & & $\begin{array}{l}10 \mathrm{mg} / \mathrm{kg} \mathrm{IP} \\
21 \text { days }+ \text { acute stress }\end{array}$ & & $\begin{array}{l}\text { Hippocampus } \\
\text { PFC }\end{array}$ & & \\
\hline & $\downarrow$ & $\begin{array}{l}0.08 \mathrm{mg} / \mathrm{kg} \mathrm{SC} \\
\text { Acute }\end{array}$ & $\mathrm{SD}$ rats & Striatum & RT-PCR & Waters et al. [96] \\
\hline \multirow[t]{2}{*}{ BDNF } & $\downarrow$ & $\begin{array}{l}10 \mathrm{mg} / \mathrm{kg} \mathrm{IP} \\
21 \text { days }\end{array}$ & SD rats & Hippocampus & qRT-PCR & Luoni et al. [133] \\
\hline & $\uparrow$ & $\begin{array}{l}10 \mathrm{mg} / \mathrm{kg} \mathrm{IP} \\
21 \text { days }+ \text { acute stress }\end{array}$ & & PFC & & \\
\hline
\end{tabular}

$A C C$ anterior cingulate cortex, $C P$ caudate putamen, $F r C$ frontal cortex, IP intraperitoneal, $I S H H$ in situ hybridization histochemistry, $P F C$ prefrontal cortex, $P O$ per oral, $q R T-P C R$ quantitative reverse transcriptase polymerase chain reaction, $S C$ subcutaneous, $S D$ Sprague Dawley

prolactin mRNAs [86], thus providing molecular ground for the clinical observation that aripiprazole may be beneficial in reducing antipsychotic-induced hyperprolactinemia [87].

Aripiprazole has been also shown to impact gene expression related to neurotransmitter systems other than dopamine. Sub-chronic (1 week) administration of aripiprazole has been associated with an increase in 5-HT1AR binding in the hippocampus, although without an increase in 5-HT1AR mRNA expression. However, these effects do not last after chronic aripiprazole administration [88]. Moreover, unlike olanzapine, aripiprazole has been demonstrated not to impact H1R mRNA expression in the arcuate hypothalamic nucleus, which is directly correlated with food intake and weight gain associated with antipsychotics [89]. Increased expression of muscarinic M1 receptors (M1R) mRNA in the hippocampus and nucleus accumbens has been reported with both sub-chronic and chronic aripiprazole administration in rats, with no impact on nigrostriatal M1R expression, which may be modulated by olanzapine and haloperidol [90].

With regards to GABAergic neurotransmission, chronic aripiprazole has been demonstrated to reduce mRNA expression of the glutamic acid decarboxylase (GAD67) gene, which codes for the predominating enzyme that synthesizes GABA, in the caudate putamen, prefrontal cortex, and somatosensory cortex, whereas GAD67 gene expression may be induced in the hippocampus, hypothalamus, thalamus, and amygdala. Several other significant changes were found in mRNA expression of the genes coding for the vesicular GABA transporter (Slc32a1), and the transmembrane transporter Slc6a1 and Slc6a11 [91].

Aripiprazole may also induce mRNA expression of NR1, NR2A, and NR2C subunits of the $N$-methyl-D-aspartate (NMDA) receptor after chronic treatment, with a concurrent reduction of NR2B subunit, thereby shifting the NR2A/NR2B ratio to an adult-type nMDA receptor composition, with consequent enhancement of nMDA function 
and expression [92]. Aripiprazole has been demonstrated to affect the expression of genes coding for glutamate transporters. Specifically, chronic aripiprazole may suppress mRNA expression of the glial excitatory amino acid transporter genes EAAT1 and EAAT2 and of the neuronal transporter EAAT3 in hippocampal sub-regions and of EAAT4 in the frontal cortex, whereas it may enhance the expression of the presynaptic vesicular glutamate transporter vGluT1 in the hippocampus [93], thus strengthening glutamate neurotransmission in these areas.

Overall, the above-mentioned gene expression studies showed that aripiprazole may exert complex dose- and time-dependent effects on multiple neurotransmitter systems beyond the aripiprazole receptor profile, as they also involve systems, such as the glutamatergic system, that are not directly targeted by the compound. These studies suggest that a wide and yet to be fully characterized range of molecular effects are induced by aripiprazole in the central nervous system, and allow the hypothesis that these effects may be more useful to explain the global therapeutic efficacy and long-term neurobiology of the compound beyond its receptor profile.

Indeed, recent microarray and quantitative real-time polymerase chain reaction (qRT-PCR) studies have identified multiple genes modulated by aripiprazole [94], including the up-regulation of early growth response genes 1, 2, 4 (Egr1, Egr2, Egr4), chromobox homolog 7 (Cbx7), cannabinoid receptor $(\mathrm{Cnr} 1)$, catechol- $O$-methyltransferase (Comt), protein phosphatase $2 \mathrm{c}$, magnesium-dependent (Ppm2c), tachykinin receptor 3 (Tacr3), Wiskott-Aldrich syndrome-like gene (Wasl), and DNA methyltransferase 3a (Dnmt3a) [94].

Gene expression analysis has also demonstrated the impact of aripiprazole on molecules implicated in synaptic plasticity [95]. RT-PCR experiments have shown that aripiprazole may reduce mRNA expression of activityregulated cytoskeleton-associated protein/activity-regulated gene 3.1 (Arc, an immediate-early gene that is induced by synaptic activity and regulates cytoskeleton rearrangements in dendritic spines) in rat striatum, whereas haloperidol may increase it [96].

Several studies have reported that aripiprazole may modulate the expression of Homer family genes, which are synaptic plasticity-related genes encoded in distinct isoforms, including inducible (i.e. Homerla and ania-3) and constitutive (i.e. Homer $1 b / 1 c / 2 / 3$ ) variants [97]. Homer proteins are implicated in downstream glutamatergic signaling and in architectural and functional molecular adaptations within the postsynaptic density microdomain of dendritic spines [1, 98]. The inducible early gene Homerla is significantly induced by antipsychotics according to their antidopaminergic profile [99-103], and its expression is significantly modulated by selective blockade of D2Rs [104] as well as by compounds acting on the glutamatergic system $[105,106]$. After acute administration, mRNA expression of Homerla may be significantly induced in the rat caudate putamen by low doses of aripiprazole, whereas cortical gene expression may be only induced by high doses of aripiprazole [81]. Chronic treatment with aripiprazole induces Homerla mRNA expression in both the cortex and the lateral striatum [81]. These data demonstrate that aripiprazole has a strong impact on plasticity-related genes, in either acute or chronic administration paradigms, and highlight the differential modulation of Homerla by aripiprazole compared with compounds regulating dopaminergic neurotransmission differently, such as haloperidol, which prevalently stimulates Homerla striatal expression, or clozapine, which has a predominantly cortical impact on gene expression [68].

Recent evidence suggests that aripiprazole may also indirectly modulate glutamatergic signaling in key brain areas for antipsychotic therapy, such as the lateral striatum and the anterior cingulate cortex. Among proteins that have been linked to abnormal synaptic plasticity believed to be involved in schizophrenia is neuregulin 1 (NRG1), a family of epidermal growth factor (EGF)-like domain-containing trophic factors [107] interacting with ErbB-4 receptor and strictly linked to the postsynaptic density (PSD) function. NRG1 gene has been identified as a schizophrenia susceptibility gene in different populations [108], and the downregulation of $n r g l$ in mice expressing high levels of the protein is able to counteract the psychotic-like behavioral abnormalities of these animals [109]. A link between NRG1 and D2Rs in controlling psychotic-like behavior in rodents has recently been shown [110]. Distinct temporal and spatial downregulation may be induced by chronic aripiprazole, olanzapine, or haloperidol treatment on different NRG1 isoforms, thus confirming the unique features of functional selectivity among antipsychotic drugs [111].

\section{Long-Term Effects of Aripiprazole Treatment on Dopamine-Dependent Synaptic Plasticity}

Although schizophrenia has often been considered a disrupting disorder with a natural course of illness that is difficult to predict and depends strongly on individual variability [112], for the most part current evidence shows that antipsychotic medications are still the mainstay treatments for this disease and that continuing therapy may prevent a large percentage of relapses [113]. Moreover, non-optimal adherence or withdrawal from antipsychotic therapy has been classified as an unequivocal risk of relapse, with a progressively worse outcome [114]. The beneficial effects of a long treatment duration on the pathophysiology of the disease as well as on dopamine 
dynamics may be largely improved by continuous treatment with antipsychotics in the LAI formulation.

Development of LAI antipsychotics started in the 1960s with the aim of overcoming non-adherence [115]. However, a large body of evidence highlights the slight differences in effectiveness, as well as the non-significant advantages, between oral and long-acting antipsychotics [116], although mirror studies in patients eligible for LAI antipsychotics demonstrate a significant superiority of LAI over daily administration of oral antipsychotics. However, methodological issues should be taken carefully into consideration when discussing the results of studies comparing oral and LAI antipsychotic formulations. A recent metaanalysis of randomized controlled trials (RCTs) assessing the benefits of LAI over oral antipsychotics failed to find significant differences between the two types of formulations in multiple primary and secondary outcome measures, including prevention of relapse at the longest and at intermediate time-points, all-cause discontinuation, drug inefficacy, and non-adherence [117]. Nonetheless, the authors of this meta-analysis cast substantial doubts on the reliability of RCTs as the best method to study the issue. It appears that standard RCTs may not be the most correct method to compare these two types of formulations; trial participants may over-represent patients with a good engagement with healthcare providers and who are more likely to be adherent than patients in naturalistic conditions [117]. On the other hand, naturalistic and mirror studies may represent a more reliable design for affordable comparisons [116, 118]. Mirror studies compare a period of LAI treatment and oral antipsychotic treatment in the same patients and therefore might better capture potential differences in the outcomes considered [117].

However, preclinical studies have repeatedly reported significant, although often conflicting, differences in transient oral (or injected) antipsychotic administration compared with continuous infusion by means of appropriate devices (e.g. osmotic minipumps, depot formulations). In both human and animal studies, when defining the action of a particular antipsychotic drug, considerable attention is given to the threshold of occupancy of D2Rs reached by this drug that correlates with clinical and side effects, and may also be useful to differentiate each drug and to understand its molecular actions [119].

Preclinical animal studies have demonstrated that both first-generation and second-generation antipsychotics when administered in continuous infusion by means of minipumps, despite reaching a lower occupancy of D2Rs than transient injections, induce higher rates of EPS [120, 121]. Moreover, Samaha et al. [122] recently demonstrated that continuous infusion of haloperidol shows reduced behavioral effects than transient within-day injection, even when continuously infused drug doses are tenfold higher than transient injected drug doses. These findings may be attributable to an increase in high-affinity state striatal D2R numbers achieved by continuous treatment compared with transient treatment. Furthermore, it seems also that postsynaptic effects might be different if equivalent doses of drugs are administered with different kinetics. In the same experiments, the authors found that only transient haloperidol may activate striatal c-fos mRNA expression [122].

Similarly to animal studies, human PET and single photon emission computed tomography (SPECT) analyses revealed that LAI antipsychotics continuously and stably block D2Rs, albeit reaching consistently lower maximal occupancy rates than transient drug administrations (often $\leq 65 \%$ ) [123]. Moreover, this lower occupancy does not always correspond to reduced control of symptoms, thereby suggesting that high rates of D2R occupancy are not needed for maintenance therapy.

However, clinical studies comparing oral with LAI antipsychotics have often produced contrasting results, some showing lower efficacy and higher propensity for inducing side effects in the continuous treatments [124], and some showing pronounced superiority of the LAI drugs compared with oral drugs [125]. In summary, recent evidence demonstrates that new LAI formulations appear to be equal or superior to their oral equivalent drugs, whereas old depot formulations may have a higher propensity for inducing side effects and lower efficacy compared with the corresponding first-generation antipsychotics [126].

In a recent double-blind RCT, an aripiprazole LAI formulation demonstrated significantly higher efficacy than placebo and a good tolerance in maintenance therapy for schizophrenic patients [127]. Moreover, its non-inferiority compared with oral aripiprazole was also demonstrated [128], as well as its safety and tolerability in patients previously stabilized with other antipsychotics [129].

\subsection{Comparison with Other Antipsychotics}

Despite the potentially strong interest for clinical applications, only a few studies have been performed to investigate the effects of continuous administration of aripiprazole on dopamine signaling in preclinical paradigms. In this regard, it can be helpful to first consider the effect of chronic but not continuous (i.e. chronic daily oral administration) aripiprazole treatment and then shift the focus to studies addressing the effects of chronic parenteral continuous treatment. Different modulation of dopamine neurotransmission between first- and new-generation antipsychotics has been reported. For instance, early studies demonstrated that chronic aripiprazole may exert dopamine antagonist activity at striatal neurons (i.e. nonsignificant rise in [H3]spiperone binding and inhibition of 
quinpirole-evoked GTPase activity), yet without increasing D2R mRNA expression, whereas haloperidol strongly raises them [130]. Similarly, no effects on prolactin and decreased spiperone binding could be observed in pituitary cells with chronic aripiprazole, whereas haloperidol and sulpiride strongly enhance both parameters [86].

With regards to dopamine metabolism in the forebrain, microdialysis studies found that acute aripiprazole has no effects on dopamine release in either the medial prefrontal cortex or the striatum, whereas it may strongly increase levels of dopamine extracellular metabolites and inhibit levels of extracellular serotonin metabolites in both regions. In contrast, chronic administration of aripiprazole produces a 'stabilization' of dopaminergic effects, with a reduction in dopamine concentrations and weaker effects on both dopamine and serotonin extracellular metabolites [131]. These findings differ strongly from those obtained by acute or chronic administration of olanzapine, which both strongly and persistently increases dopamine concentrations and levels of dopamine extracellular metabolites in the medial prefrontal cortex and the striatum [131]. These effects reveal the intrinsic dopamine-stabilizing characteristics of aripiprazole in chronic paradigms. Moreover, gene expression studies also reported that chronic aripiprazole may activate gene expression programs that differ substantially from other antipsychotics. Recent microarray profiling revealed that 4 -week aripiprazole administration at clinically relevant doses may induce differential expression of genes involved in chromatin remodeling and in transcriptional regulation, all of which have been implicated in the pathophysiology of psychosis, such as catechol-O-methyl-transferase (COMT) or Dnmt3a [94]. Also, our previous work demonstrated an unusual impact of aripiprazole on synaptic plasticity genes, such as Homerla. Indeed, when acutely administered, only relatively low doses of aripiprazole induced striatal expression of Homerla and its splicing variant ania-3, similarly to haloperidol, whereas no effects were observed with higher doses [81]. In contrast, only higher dosages seem to activate Homerla cortical transcription.

Chronic aripiprazole administration, by contrast, persistently upregulated Homerla expression in the striatum, but concurrently reduced its cortical expression, with similar effects to clozapine [81]. Interestingly, no effects on D2Rs were reported with chronic aripiprazole in this study. These findings further confirm the possible balancing of dopamine synaptic release by chronic aripiprazole, which acts on both presynaptic and postsynaptic D2Rs, and consequentially tends to also 'stabilize' the postsynaptic signaling that has been altered in psychosis-like pathologic states. A further study also demonstrated that chronic aripiprazole may attenuate the downregulated expression of brain-derived neurotrophic factor (BDNF), glycogen synthase kinase-3 (GSK-3beta) and beta-catenin, which could be induced by immobilization stress [132]. Consistently, repeated aripiprazole administration has been reported to modulate the expression of Arc and neuronal PAS domain protein 4 (Npsa4) genes, both correlated to neuroplasticity, in an animal model of acute swim stress [133].

Recently, continuous infusion of aripiprazole via minipumps for 14 days was shown to maintain the levels of D2Rs in rat striatum, and have no impact on locomotor challenge responses to methamphetamine administration, these effects opposing those of haloperidol, which increased both the density of D2Rs and locomotor responses [134]. These results confirm the lack of impact of chronic aripiprazole, even when administered continuously, on dopamine supersensitivity. Dopamine supersensitivity has been conceptualized as the increase in D2R number or biological action, and may be triggered by persistent reduction of D2R activity, as in the case of chronic treatment with D2R-blocking agents. Dopamine supersensitivity could lead to a clinical condition known as 'supersensitivity' or 'breakthrough' psychosis, conceptualized as an antipsychotic-related phenomenon, and described as the re-emergence of psychotic symptoms during continuing treatment, mostly with D2R high-affinity agents $[135,136]$. Supersensitivity psychosis has been explained as the result of adaptive neurobiological processes in dopamine neurotransmission, possibly an increase in the number of high-affinity D2Rs (receptor isoforms with functional high affinity for dopamine), which may represent a subtype of antipsychotic-induced 'dopamine supersensitivity' [137]. However, several other neurobiological mechanisms could be implicated in the phenomenon of dopamine supersensitivity, including gene mutations, brain injury, or drug use [138]. Notably, it has been observed that a breakthrough psychosis can also occur as the consequence of external stressors in patients treated with low antipsychotic doses [139]. Whether this condition has to be ascribed to a relapse intrinsic to the natural history of the illness or to a combination of life events and iatrogenic dopamine supersensitivity is an intriguing matter for future studies.

Despite the lack of data, some differences among transient and continuous aripiprazole administration may be inferred from animal behavioral studies. In animal models of cocaine self-administration and subsequent extinction and reinstatement, low doses of aripiprazole administered daily before each self-administration and reinstatement sessions were demonstrated to reduce, yet not prevent, cocaine self-administration, although blocking the reinstatement of cocaine-seeking behavior [140]. In contrast, when continuously infused, aripiprazole seems to have no significant effects on cocaine self-administration or cocaine 
choice, whereas acute injection rapidly induces a reduction in seeking behavior, although only at low-intermediate doses [141]. Therefore, although more studies are needed, these experiments demonstrated the effect of aripiprazole in both acute and chronic paradigms, with different effects at different doses. Moreover, like other antipsychotics, transient administration produces differential effects than continuous infusion, the kinetics of which are yet to be determined. The role of the duration of treatment with antipsychotics is relevant also for the prediction of antipsychotic response and maintenance of response [142]. Approximately $30 \%$ of patients do not respond or respond poorly to antipsychotic therapy and are defined as treatment resistant [143]. Multiple factors have been suggested as the origin of true treatment resistance to antipsychotics, including, among others, genetic variability in dopamine receptor and other neurotransmitter receptor responsiveness [144-147] and aberrant brain morphology, such as gray matter loss in cortical and sub-cortical regions [3].

\subsection{Prevention of Resistance to Antipsychotic Treatment}

One unmet need in treatment-resistant schizophrenia is the management of progressive loss of effect after successful prolonged treatment. In other words, after responding to an antipsychotic given at the correct dose for an extended period of time, a patient may experience a relapse with increasing intensity of symptom severity despite good adherence to therapy and without the presence of modifying variables (such as drug interactions, or comorbidity with disease that may jeopardize antipsychotic drug treatment) [148].

Even if the mechanism behind this condition is unresolved, one hypothesis that has been strongly backed up by experimental preclinical evidence states that prolonged treatment with antipsychotics that have high affinity for D2Rs may progressively induce increased D2R binding, most probably by increasing the number of high-affinity D2Rs (and possibly also D2R maximal specific binding, $\left.B_{\max }\right)$, making the D2Rs more sensitive to dopamine [148].

Interestingly, it has been postulated that an increased number of high-affinity D2Rs is the common final pathway of multiple and different pharmacological manipulations (dopamine antagonists, dopamine indirect agonist, cesarean birth), even those not directly related to the dopamine system, and that the increase in high-affinity D2Rs is a key event in the susceptibility to developing a psychosis-like behavior in animal models of schizophrenia [137]. If the correlation between an increase in high-affinity D2Rs and progressive reduction in response to antipsychotics is indeed further confirmed, the lack of increase in highaffinity D2Rs after chronic aripiprazole treatment by means of continuous infusion (intraperitoneal minipump) compared with chronic full antagonist treatment such as haloperidol [134] may suggest that biased ligands may potentially prevent or delay, in adult animals but not in juvenile rodents [84], the postulated consequences of the increase in high-affinity D2Rs, such as the onset of resistance to antipsychotic treatment after a period of adequate response. This observation should be considered together with the finding that repeated administration of aripiprazole produces, as with other D2R-acting antipsychotics, a sensitization effect in the suppression of conditioned avoidance response (i.e. avoiding foot shock) without impairing the escape response (i.e. motor ability) and phencyclidineinduced hyperlocomotion, a feature considered highly predictive of antipsychotic activity [149].

\section{New Partial Agonists for Potential Use in Schizophrenia}

Despite that the pharmacological action of aripiprazole has now been more precisely conceptualized as depending on functional selectivity at dopamine receptors, which in some cases may have the features of partial agonism at D2Rs and of a 'dopamine stabilizer' in the synapse [150, 151], new drugs with postulated partial agonist properties have been developed endeavoring to resemble the supposed 'partial agonist' characteristics of aripiprazole.

However, the development of new partial dopaminergic agonists has been slowed, and potentially impaired, by the evidence of the 'unusual' partial agonism of aripiprazole at dopamine D2R/D3Rs. Aripiprazole may act as a complete full agonist or a full antagonist according to the context in which its functions are investigated; these features are unique compared with other classical partial agonists. Therefore, aripiprazole has been regarded as a unique 'functionally selective' ligand [36, 42]; that is, a drug that may show different intrinsic activity at different receptor subclasses in the synapse, or that may cause multiple functional effects, even when interacting with the same receptor.

Other drugs have been described as holding functional selectivity at dopamine D2R/D3Rs in early studies, even if they often did not show sufficient preclinical or clinical features to be considered as possibly efficacious antipsychotics. For instance, dihydrexidine (DHX) and $N-n$ propyldihydrexidine (propylDHX) were originally screened as full D1R agonists, but they also showed D2R affinity [152]. Specifically, when tested for D2R intrinsic activity, both DHX and propylDHX demonstrated full D2R agonist activity at postsynaptic D2Rs by inhibiting adenylate cyclase, yet an opposite antagonist action at the presynaptic D2R-mediated inhibition of dopamine release [153, 154]. Although also showing interesting antipsychotic features in 
behavioral studies (i.e. block of amphetamine-induced hyperactivity, disrupting of pre-pulse inhibition with no effects on startle responses) [155, 156], only a few clinical studies have been published on the efficacy of DHX in humans. These have demonstrated an increased prefrontal perfusion after a single dose of DHX in schizophrenia patients as well as a good safety and tolerability of a daily 20-mg single dose, although without any improvement in cognitive performances [157, 158]. However, a recent study in unmedicated patients with schizotypal personality disorder meeting criteria for cognitive impairment showed that DHX administration significantly ameliorated verbal working memory [159]. Although DHX administration occurred in a very limited time window, the lack of psychotic rebound by this D1R/D2R full agonist suggests a functional selectivity on D2R-mediated downstream signaling. Replication studies, with prolonged DHX administration, are needed to corroborate this view.

Concurrently with the development of aripiprazole, other quinolinone derivatives showed different degrees of intrinsic activity. OPC-4392 was the predecessor of aripiprazole on the development pipeline and it showed agonist activity at presynaptic D2Rs and antagonist activity at postsynaptic receptors, with behavioral correlates in preclinical studies [159]. However, clinical trials demonstrated a worsening in psychotic symptoms [160].

Among the 'oldest' dopamine partial agonists studied is terguride, an ergot alkaloid originally tested in neurologic pathologies, such as Parkinson's disease and hyperprolactinemia [161-163]. Several studies have demonstrated that terguride possesses classical partial agonist features, thereby acting as an antagonist in hyperdopaminergic environments and as an agonist in hypodopaminergic environments [164-166]. More recent studies showed that terguride holds higher intrinsic activity in in vitro assays than aripiprazole [167] and that this could be a detriment to its use as a therapeutic drug. Moreover, both preclinical behavioral $[54,168]$ and molecular studies [81, 104] confirmed the substantial differences between terguride and aripiprazole, which may represent possible reasons for the clinical failure of terguride. However, a recent study identified 2-bromoterguride, a halogen derivative of terguride, as a likely antipsychotic candidate in human studies, because of its lower intrinsic activity at hD2Rs (half that of terguride), a high affinity to 5-HT2ARs, and an ability to inhibit amphetamine-induced hyperlocomotor activity in rats without inducing catalepsy [169].

Several other compounds with potential aripiprazolelike functional effects have been tested for antipsychotic efficacy, with contradictory results.

Talipexole is an azepine derivative classified as a D2R agonist agent. Some early studies suggested a partial agonist activity of this compound because of its ability to inhibit the $\gamma$-butyrolactone-induced increase in dopamine striatal synthesis without inducing hyperactivity in mice, thus indicating full agonist properties at presynaptic D2Rs [170]. However, when clinically tested for the treatment of schizophrenia, only a scarce but significant reduction in negative symptoms score was found, without effects on positive symptoms [171].

Similar observations were carried out for roxindole, an indole derivative originally developed for the treatment of schizophrenia. Early pharmacological studies revealed that this drug holds a functionally selective agonist activity at presynaptic D2R autoreceptors that was higher than that displayed by talipexole, together with 5-HT1AR agonist and serotonin re-uptake inhibiting activities, all properties confirmed by behavioral studies [172]. However, clinical trials demonstrated only scarce effects on negative symptoms of schizophrenia and no effects on positive symptoms [173].

$N$-[(8 $\alpha$ )-2-Chloro-6-methylergolin-8-yl]-2,2-dimethylpropanamide (SDZ 208-912) is an amino-ergoline compound that showed D2R partial agonist and low intrinsic activity in early biochemical assays [174, 175]. Comparative studies have demonstrated that SDZ 208-912 displays higher intrinsic activity than aripiprazole and lower antagonist properties at D2Rs, both features that may potentially account for suboptimal results in treating psychotic symptoms [176].

Pharmacological studies on aminopyrimidine derivatives revealed that trans-\{4-[2-(4-phenyl-piperazin-1-yl)ethyl]-cyclohexyl\}-pyrimidin-2-yl-amine (PD 158771) may display partial agonist activity at D2Rs and D3Rs and agonist activity at 5-HT1ARs [177]. Electrophysiological studies demonstrated that PD 158771 might reduce hyperdopaminergic states induced by $\gamma$-butyrolactone administration, by acting on dopamine presynaptic autoreceptors, with a 'partial' effect compared with the agonist quinpirole [178]. In behavioral studies, PD 158771 did not produce hyperlocomotor states, yet it inhibited apomorphine-stimulated hyperlocomotion, both functions consistent with partial agonist activity [179]. To the best of our knowledge, no human studies have yet been performed.

Preclinical studies on $[R(+)-1,2,3,6$-tetrahydro-4-phenyl-1-[(3-phenyl-3-cyclohexen-1-yl)methyl]pyridine] maleate (CI-1007) also demonstrated that this compound holds potent dopamine partial agonist properties with a limited postsynaptic D2R agonist activity and a high agonist action at dopamine autoreceptors [180]. In neurophysiological studies, CI-1007 showed the ability to reduce dopaminergic nigrostriatal firing, with intrinsic activity lower than apomorphine and talipexole and higher than SDZ 208-912 [181]. Moreover, it may reduce apomorphine-induced hyperlocomotion and inhibit conditioned avoidance responses in behavioral tasks, with a low propensity to EPS 
[181, 182], thus indicating potential antipsychotic efficacy. Intravenous administration of CI-1007 in rats showed a reduction of dopamine release in the nucleus accumbens, with no effects on striatal efflux [183]. However, although initial human studies revealed good safety and tolerability in schizophrenic patients [184], no other systematic assessments on efficacy have been carried out to date.

In addition, benzamides such as amisulpride have been thought to hold partial agonist activity or functional selectivity. Amisulpride is highly selective for D2R/D3Rs and displays good efficacy on positive symptoms of schizophrenia, with the ability to also impact negative symptoms at low doses. Recent molecular studies have identified a peculiar gene expression profile for amisulpride in the rat forebrain [103], which may account for the 'atypical atypicality' of this compound. It is possible that functionally selective signaling at D2Rs may be involved in these peculiar effects of amisulpride compared with other atypical antipsychotics.

Recent pharmaceutical development pipelines led to the discovery of other new potentially antipsychotic compounds with dopamine partial agonist characteristics, such as aplindore and cariprazine.

Aplindore shows high affinity for D2 and D3Rs, with low affinity for serotonin receptors and adrenoreceptors. Functional assays showed that aplindore holds potency and intrinsic activity lower than dopamine and higher than aripiprazole [185]. In behavioral studies, aplindore showed typical partial agonist activity, for example by inducing contralateral movements in unilaterally lesioned rats [185]. However, subsequent studies abandoned the initial idea of aplindore as an antipsychotic, because of higher efficacy in treating dopamine-dependent motor disorders, such as Parkinson's disease [186, 187].

Bifeprunox was originally developed for the treatment of schizophrenia [188] and showed D2R partial agonism and 5-HT1AR agonism in an in vitro study [189]. Behavioral studies also demonstrated potential antipsychotic properties, such as inhibition of pre-pulse inhibition deficits [190]. Comparative studies demonstrated higher intrinsic activity and lower antagonistic properties at D2Rs by bifeprunox compared with aripiprazole [176]. These pharmacological differences between bifeprunox and aripiprazole have been intensely studied, and recent works demonstrated that the greater intrinsic activity at dopamine receptors with bifeprunox compared with aripiprazole might possibly be responsible for greater beneficial effects, such as weight decrease, but also for the emergence of complicating symptoms, such as anxiety, which may worsen psychosis [191].

Recent clinical studies showed significantly greater effects of bifeprunox on total primary schizophrenia symptoms compared with placebo, as well as a weight and prolactin reduction, and no induction of EPS [192]. Other studies revealed a significant lack of impact of bifeprunox on plasma glucose levels compared with other currently used atypical antipsychotics [193]. Very recent behavioral studies confirm the good antipsychotic efficacy of bifeprunox, thus stimulating further clinical assessments for this drug [54, 194]. However, despite the consistent evidence of efficacy in preclinical settings and the favorable tolerability profile, the development of bifeprunox has been discontinued, as an interim analysis showed inadequate efficacy of the compound (see http://www.clinicaltrials. gov/ct2/show/NCT00658645) and the US FDA had refused approval for marketing.

Cariprazine is a recently developed D3R-preferring partial agonist. At present, it is in late-phase clinical development for the treatment of schizophrenia. Clinical trials have demonstrated superior effects over placebo in reducing all symptoms of schizophrenia, with a low liability for metabolic symptoms and EPS [195]. However, some recent studies have claimed a relatively high incidence of movement-related disorders with cariprazine compared with other partial agonists [196, 197]. Recent clinical trials have shown good results, including the treatment of bipolar mania [197, 198]. After a prior submission of the compound to the FDA for marketing approval was rejected, an Actavis and Gedeon Richter Plc. press release on 6 January 2015 announced the new drug application (NDA) resubmission to the FDA for treatment of both schizophrenia and manic or mixed episodes associated with bipolar I disorder (see: http://www.actavis.com/ news/news/thomson-reuters); on 16 June 2015 the two companies announced the FDA had extended the review period for cariprazine to September 2015.

In the attempt to produce new compounds with dopamine partial agonist activity and functional selectivity, medicinal chemistry researchers focused their attention on the critical molecular characteristics of currently available dopamine partial agonists that seem essential for their intrinsic activity. Therefore, a careful physicochemical modification in these elements could generate compounds with a more balanced agonist/antagonist activity at D2Rs, and thus a more balanced modulation of dopaminergic signaling, namely an adequate postsynaptic D2R antagonism without suppressing dopamine-dependent psychomotor functions [199]. This new approach has led, by the physicochemical modification of a set of phenylpiperidines and phenylpiperazines, to the development of molecules with peculiar characteristics, based on which the researchers have called them 'dopamine stabilizers'. The phenylpiperidines (S)-(-)-3-(3-methanesulfonyl-phenyl)-1-propyl-piperidine [(-)-OSU6162, ordopidine] and 4-(3-methanesulfonyl-phenyl)-1-propyl)piperidine [ACR16, huntexil, pridopidine] represent two compounds developed by means of this approach. 
Pridopidine and ordopidine display neurochemical and behavioral effects that closely depend on the dopaminergic synaptic state. Indeed, first behavioral studies demonstrated that these two compounds might both reduce apomorphine/ amphetamine-induced hyperactivity and increase locomotion in hypoactive dopaminergic tone (such as apomorphine habituation) without impairing motor activity in the normal state [200-202]. Recent pharmacological studies further showed the dopamine tone-dependent activity of these drugs. Both pridopidine and ordopidine may dosedependently increase dopamine release in the striatum as well as dopamine and noradrenaline efflux in the cortex [202]. Moreover, the two phenylpiperidines display low affinity and low intrinsic activity at D2Rs in vitro, and biochemical experiments suggest a possible allosteric activity [203]. Although no studies have yet been performed in schizophrenia patients with these compounds, recent works demonstrated that both pridopidine and ordopidine might impact the forebrain expression of genes directly correlated to psychosis pathophysiology. Indeed, Natesan et al. [200] demonstrated that both the piperidines might induce preferential Fos expression in the nucleus accumbens with respect to the dorsolateral striatum, thereby confirming their atypical antipsychotic profile. Recently, significant Arc cortical induction has been shown by both the compounds compared with D1R/D2R agonists and antagonists, as well as a comparable striatal Arc induction to haloperidol, thus further confirming the peculiar antipsychotic gene expression profile of these new dopamine stabilizers [96].

Special mention should be made of brexpiprazole, a very recently developed aripiprazole derivative. Brexpiprazole could pharmacologically be considered a dopamine-serotonin modulator that combines partial agonism at 5-HT1ARs with low intrinsic activity and partial agonism at D2Rs, as well as a broad antagonist activity at multiple serotonin receptors (such as 5-HT2AR) and $\alpha$-adrenergic receptors [204]. Microdialysis experiments revealed that brexpiprazole may selectively reduce dopamine release in the nucleus accumbens and increase it in the cortex, displaying lower D2R intrinsic activity and higher 5-HT1A/ 2AR binding affinity than aripiprazole [205], thereby suggesting a more favorable antipsychotic profile than the 'kin' compound from which it is derived. Behavioral studies have confirmed the dopamine-stabilizing features of brexpiprazole. Indeed, this drug may reduce apomorphine/amphetamine-induced hyperlocomotion, and may inhibit apomorphine-induced eye blinking in monkeys [204, 205]. Moreover, brexpiprazole may reduce phencyclidine-induced cognitive impairment in rats by a D2R5-HT1AR-mediated mechanism [205, 206]. All these effects suggest that brexpiprazole can be considered a partial agonist with a balanced dopamine-serotonin activity. Recent clinical trials appear to confirm the favorable preclinical results with brexpiprazole. In a 6-week, multicenter, placebo-controlled double-blind phase III study, patients with acute schizophrenia were randomized to brexpiprazole 1,2 , or $4 \mathrm{mg}$, or placebo once daily. The tolerability profile of all doses was favorable. Brexpiprazole $4 \mathrm{mg}$ showed statistically significant improvement on the Positive and Negative Syndrome Scale (PANSS) and on the Clinical Global Impression-Severity (CGI-S) compared with placebo [207]. Clinical improvements were also seen with lower dosages of brexpiprazole compared with placebo, but they did not reach statistical significance [207]. Several other clinical trials on brexpiprazole in the treatment of schizophrenia and major depressive disorder are still ongoing or have been recently completed (see http://www.clinicaltrials.gov). Results of these studies have been the object of some poster or oral communications in scientific meetings and appear appealing; however, they have not been published in detail and require replication.

\section{Final Remarks}

Despite recent experimental data diminishing the actual pharmacological relevance in the mechanism of action of antipsychotics, the introduction of the concept of partial agonism at D2Rs has represented a breakthrough in recent schizophrenia therapy, since it has allowed consideration under a different perspective the 'no-efficacy-without-D2R blockade' dogma that has been central in the pharmacological therapy of psychosis over the last 50 years.

Even if considered classically as a D2R partial agonist, multiple lines of evidence suggest that aripiprazole acts at D2Rs impacting the dopaminergic system in different ways, depending on the contingent conditions in which the biological system is examined. Therefore, aripiprazole has been described as a full antagonist, a moderate antagonist, or a partial agonist at D2Rs in different preclinical paradigms, consistent with biased ligand features of the compound. The 'adaptive' features of aripiprazole are strikingly different from all other antipsychotics, the action of which remains relatively stable in all biological conditions. One main consequence of this feature is that using aripiprazole may prevent the development of long-term dopamine-related neurochemical adaptations that may possibly affect long-term response to antipsychotics. Indeed, chronic treatment with aripiprazole has been observed to prevent the development of dopamine supersensitivity [134]. While the intermediate intrinsic activity of aripiprazole at D2Rs may per se represent a suitable explanation for the lack of dopamine supersensitivity, it cannot be excluded that this may depend on the 
pharmacological action of aripiprazole, which ranges from agonism to antagonism and therefore oscillates between stimulation and inactivation of the receptor.

The other relevant consequence of the 'adaptive' feature of aripiprazole is that the pharmacological action of the compound may strictly depend on, among other mechanisms, the endogenous dopamine levels and signaling status.

In conclusion, the introduction of aripiprazole to the treatment of schizophrenia and other psychiatric diseases has paved the way for a new generation of compounds that not only block dopaminergic transmission via D2Rs but may also be conceptualized as dynamic-acting D2R modulators beyond dopamine antagonism.

\section{Compliance with Ethical Standards}

Funding This work was partly supported by an unrestricted grant from Otsuka Italia to Andrea de Bartolomeis. The design, implications, and conclusions of the manuscript are solely the responsibility of the authors, and the funding source had no role in the conception, design, or content of the manuscript. We thank Ray Hill, an independent medical writer, who provided copyediting and journal styling prior to submission, on behalf of Springer Healthcare Communications. We also thank Simone Boniface, of Springer Healthcare Communications, who provided post-submission English editing. This assistance and open access was funded by Otsuka Italia.

Conflicts of interest AdB: research grant from Lundbeck; unrestricted research grant from Otsuka; participation in advisory boards for Janssen, Roche, Otsuka, and Lundbeck; speaker in educational CME activities sponsored by unrestricted grants from Janssen, Roche, Otsuka, and Lundbeck. FI and CT: no conflicts of interest to declare.

Open Access This article is distributed under the terms of the Creative Commons Attribution-NonCommercial 4.0 International License (http://creativecommons.org/licenses/by-nc/4.0/), which permits any noncommercial use, distribution, and reproduction in any medium, provided you give appropriate credit to the original author(s) and the source, provide a link to the Creative Commons license, and indicate if changes were made.

\section{References}

1. de Bartolomeis A, Buonaguro EF, Iasevoli F. Serotonin-glutamate and serotonin-dopamine reciprocal interactions as putative molecular targets for novel antipsychotic treatments: from receptor heterodimers to postsynaptic scaffolding and effector proteins. Psychopharmacology (Berl). 2013;225(1):1-19.

2. Howes OD, Kapur S. The dopamine hypothesis of schizophrenia: version III-the final common pathway. Schizophr Bull. 2009;35(3):549-62.

3. de Bartolomeis A, Latte G, Tomasetti C, et al. Glutamatergic postsynaptic density protein dysfunctions in synaptic plasticity and dendritic spines morphology: relevance to schizophrenia and other behavioral disorders pathophysiology, and implications for novel therapeutic approaches. Mol Neurobiol. 2014;49(1):484-511.
4. Hall J, Trent S, Thomas KL, et al. Genetic risk for schizophrenia: convergence on synaptic pathways involved in plasticity. Biol Psychiatry. 2015;77(1):52-8.

5. Wen Z, Nguyen HN, Guo Z, et al. Synaptic dysregulation in a human iPS cell model of mental disorders. Nature. 2014;515(7527):414-8.

6. van den Heuvel MP, Fornito A. Brain networks in schizophrenia. Neuropsychol Rev. 2014;24(1):32-48.

7. Usun Y, Eybrard S, Meyer F, et al. Ketamine increases striatal dopamine release and hyperlocomotion in adult rats after postnatal functional blockade of the prefrontal cortex. Behav Brain Res. 2013;256:229-37.

8. Breier A, Su TP, Saunders R, et al. Schizophrenia is associated with elevated amphetamine-induced synaptic dopamine concentrations: evidence from a novel positron emission tomography method. Proc Natl Acad Sci USA. 1997;94(6):2569-74.

9. Kapur S, Mamo D. Half a century of antipsychotics and still a central role for dopamine D2 receptors. Prog Neuropsychopharmacol Biol Psychiatry. 2003;27(7):1081-90.

10. FDA U. Inventor drug approval package, Abilify (aripiprazole) tablets. http://www.accessdata.fda.gov/scripts/cder/drugsatfda/ index.cfm?fuseaction=Search.DrugDetails2002.

11. FDA U. Inventor drug approval package, Abilify (aripiprazole) solution. http://www.accessdata.fda.gov/scripts/cder/drugsatfda/ index.cfm?fuseaction=Search.DrugDetails2004.

12. Kim JR, Seo HB, Cho JY, et al. Population pharmacokinetic modelling of aripiprazole and its active metabolite, dehydroaripiprazole, in psychiatric patients. Br J Clin Pharmacol. 2008;66(6):802-10.

13. Grunder G, Fellows C, Janouschek H, et al. Brain and plasma pharmacokinetics of aripiprazole in patients with schizophrenia: an [18F]fallypride PET study. Am J Psychiatry. 2008;165(8):988-95.

14. Yokoi F, Grunder G, Biziere K, et al. Dopamine D2 and D3 receptor occupancy in normal humans treated with the antipsychotic drug aripiprazole (OPC 14597): a study using positron emission tomography and [11C]raclopride. Neuropsychopharmacology. 2002;27(2):248-59.

15. Kirschbaum KM, Muller MJ, Malevani J, et al. Serum levels of aripiprazole and dehydroaripiprazole, clinical response and side effects. World J Biol Psychiatry. 2008;9(3):212-8.

16. FDA U. Drug approval package, Abilify (aripiprazole) intramuscular injectable solution. 2006. http://www.accessdata.fda.gov/scripts/ cder/drugsatfda/index.cfm?fuseaction=Search.DrugDetails.

17. FDA U. Drug approval package, Abilify Maintena (aripiprazole), extended-release intramuscular injectable solution. 2013. http:// www.accessdata.fda.gov/scripts/cder/drugsatfda/index.cfm? fuseaction=Search.DrugDetails.

18. Raoufinia A, Baker RA, Eramo A, et al. Initiation of aripiprazole once-monthly in patients with schizophrenia. Curr Med Res Opin. 2015;31(3):583-92.

19. Kubo M, Koue T, Inaba A, et al. Influence of itraconazole coadministration and CYP2D6 genotype on the pharmacokinetics of the new antipsychotic ARIPIPRAZOLE. Drug Metab Pharmacokinet. 2005;20(1):55-64.

20. Kubo M, Koue T, Maune H, et al. Pharmacokinetics of aripiprazole, a new antipsychotic, following oral dosing in healthy adult Japanese volunteers: influence of CYP2D6 polymorphism. Drug Metab Pharmacokinet. 2007;22(5):358-66.

21. Lamba JK, Lin YS, Schuetz EG, et al. Genetic contribution to variable human CYP3A-mediated metabolism. Adv Drug Deliv Rev. 2002;54(10):1271-94.

22. Azuma J, Hasunuma T, Kubo M, et al. The relationship between clinical pharmacokinetics of aripiprazole and CYP2D6 genetic polymorphism: effects of CYP enzyme inhibition by 
coadministration of paroxetine or fluvoxamine. Eur $\mathrm{J}$ Clin Pharmacol. 2012;68(1):29-37.

23. de Bartolomeis A, Perugi G. Combination of aripiprazole with mood stabilizers for the treatment of bipolar disorder: from acute mania to long-term maintenance. Expert Opin Pharmacother. 2012;13(14):2027-36.

24. Citrome L, Macher JP, Salazar DE, et al. Pharmacokinetics of aripiprazole and concomitant carbamazepine. J Clin Psychopharmacol. 2007;27(3):279-83.

25. Mallikaarjun S, Kane JM, Bricmont P, et al. Pharmacokinetics, tolerability and safety of aripiprazole once-monthly in adult schizophrenia: an open-label, parallel-arm, multiple-dose study. Schizophr Res. 2013;150(1):281-8.

26. Molden E, Lunde H, Lunder N, et al. Pharmacokinetic variability of aripiprazole and the active metabolite dehydroaripiprazole in psychiatric patients. Ther Drug Monit. 2006;28(6): 744-9.

27. Koch I, Weil R, Wolbold R, et al. Interindividual variability and tissue-specificity in the expression of cytochrome P450 3A mRNA. Drug Metab Dispos. 2002;30(10):1108-14.

28. Kenakin T. Agonist-specific receptor conformations. Trends Pharmacol Sci. 1997;18(11):416-7.

29. Kenakin T, Williams M. Defining and characterizing drug/compound function. Biochem Pharmacol. 2014;87(1): 40-63.

30. Urban JD, Clarke WP, von Zastrow M, et al. Functional selectivity and classical concepts of quantitative pharmacology. J Pharmacol Exp Ther. 2007;320(1):1-13.

31. Zhu J, Taniguchi $\mathrm{T}$, Takauji $\mathrm{R}$, et al. Inverse agonism and neutral antagonism at a constitutively active alpha-1a adrenoceptor. Br J Pharmacol. 2000;131(3):546-52.

32. Kenakin T. Functional selectivity: theoretical consideration and future direction. In: Neve KA, editor. Functional selectivity of G protein-coupled receptor ligands. New York: Humana Press; 2009. p. 9-24.

33. Mailman R, Wang YM, Kant A, et al. Functional selectivity at dopamine receptors. In: Neve KA, editor. Functional selectivity of $\mathrm{G}$ protein-coupled receptor ligands. New York: Humana Press; 2009. p. 177-209.

34. Mailman RB, Murthy V. Ligand functional selectivity advances our understanding of drug mechanisms and drug discovery. Neuropsychopharmacology. 2010;35(1):345-6.

35. Mailman RB, Murthy V. Third generation antipsychotic drugs: partial agonism or receptor functional selectivity? Curr Pharm Des. 2010;16(5):488-501.

36. Shapiro DA, Renock S, Arrington E, et al. Aripiprazole, a novel atypical antipsychotic drug with a unique and robust pharmacology. Neuropsychopharmacology. 2003;28(8):1400-11.

37. Burris KD, Molski TF, Xu C, et al. Aripiprazole, a novel antipsychotic, is a high-affinity partial agonist at human dopamine D2 receptors. J Pharmacol Exp Ther. 2002;302(1):381-9.

38. Kane JM, Carson WH, Saha AR, et al. Efficacy and safety of aripiprazole and haloperidol versus placebo in patients with schizophrenia and schizoaffective disorder. J Clin Psychiatry. 2002;63(9):763-71.

39. Tadori Y, Forbes RA, McQuade RD, et al. Functional potencies of dopamine agonists and antagonists at human dopamine $\mathrm{D}(2)$ and D(3) receptors. Eur J Pharmacol. 2011;666(1-3):43-52.

40. Tadori Y, Forbes RA, McQuade RD, et al. In vitro pharmacology of aripiprazole, its metabolite and experimental dopamine partial agonists at human dopamine D2 and D3 receptors. Eur J Pharmacol. 2011;668(3):355-65.

41. Bruins Slot LA, Palmier C, Tardif S, et al. Action of novel antipsychotics at human dopamine D3 receptors coupled to $\mathrm{G}$ protein and ERK1/2 activation. Neuropharmacology. 2007;53 (2):232-41.
42. Urban JD, Vargas GA, von Zastrow M, et al. Aripiprazole has functionally selective actions at dopamine D2 receptor-mediated signaling pathways. Neuropsychopharmacology. 2007;32(1): 67-77.

43. Hamamura T, Harada T. Unique pharmacological profile of aripiprazole as the phasic component buster. Psychopharmacology (Berl). 2007;191(3):741-3.

44. Ma GF, Raivio N, Sabria J, et al. Agonist and antagonist effects of aripiprazole on $\mathrm{D}(2)$-like receptors controlling rat brain dopamine synthesis depend on the dopaminergic tone. Int $\mathbf{J}$ Neuropsychopharmacol. 2015;18(4).

45. Lawler CP, Prioleau C, Lewis MM, et al. Interactions of the novel antipsychotic aripiprazole (OPC-14597) with dopamine and serotonin receptor subtypes. Neuropsychopharmacology. 1999;20(6):612-27.

46. Mailman RB. GPCR functional selectivity has therapeutic impact. Trends Pharmacol Sci. 2007;28(8):390-6.

47. Shan J, Khelashvili G, Mondal S, et al. Ligand-dependent conformations and dynamics of the serotonin 5-HT(2A) receptor determine its activation and membrane-driven oligomerization properties. PLoS Comput Biol. 2012;8(4):e1002473.

48. Kofuku Y, Ueda T, Okude J, et al. Efficacy of the beta(2)adrenergic receptor is determined by conformational equilibrium in the transmembrane region. Nat Commun. 2012;3: 1045.

49. Kling RC, Tschammer N, Lanig H, et al. Active-state model of a dopamine $\mathrm{d} 2$ receptor-galphai complex stabilized by aripiprazole-type partial agonists. PLoS One. 2014;9(6):e100069.

50. Heusler P, Newman-Tancredi A, Castro-Fernandez A, et al. Differential agonist and inverse agonist profile of antipsychotics at D2L receptors coupled to GIRK potassium channels. Neuropharmacology. 2007;52(4):1106-13.

51. Kikuchi T, Tottori K, Uwahodo Y, et al. 7-(4-[4-(2,3-Dichlorophenyl)-1-piperazinyl]butyloxy)-3,4-dihydro-2(1H)-quinolinon e (OPC-14597), a new putative antipsychotic drug with both presynaptic dopamine autoreceptor agonistic activity and postsynaptic D2 receptor antagonistic activity. J Pharmacol Exp Ther. 1995;274(1):329-36.

52. Lahti AC, Weiler MA, Corey PK, et al. Antipsychotic properties of the partial dopamine agonist (-)-3-(3-hydroxyphenyl)- $N-n$ propylpiperidine(preclamol) in schizophrenia. Biol Psychiatry. 1998;43(1):2-11.

53. Olbrich R, Schanz H. An evaluation of the partial dopamine agonist terguride regarding positive symptoms reduction in schizophrenics. J Neural Transm Gen Sect. 1991;84(3):233-6.

54. Natesan S, Reckless GE, Barlow KB, et al. Partial agonists in schizophrenia - why some work and others do not: insights from preclinical animal models. Int $\mathbf{J}$ Neuropsychopharmacol. 2011;14(9):1165-78.

55. Newman-Tancredi A, Assie MB, Leduc N, et al. Novel antipsychotics activate recombinant human and native rat serotonin 5-HT1A receptors: affinity, efficacy and potential implications for treatment of schizophrenia. Int J Neuropsychopharmacol. 2005;8(3):341-56.

56. Jordan S, Koprivica V, Chen R, et al. The antipsychotic aripiprazole is a potent, partial agonist at the human 5-HT1A receptor. Eur J Pharmacol. 2002;441(3):137-40.

57. Stark AD, Jordan S, Allers KA, et al. Interaction of the novel antipsychotic aripiprazole with 5-HT1A and 5-HT 2A receptors: functional receptor-binding and in vivo electrophysiological studies. Psychopharmacology (Berl). 2007;190(3):373-82.

58. Millan MJ. Improving the treatment of schizophrenia: focus on serotonin (5-HT)(1A) receptors. J Pharmacol Exp Ther. 2000; 295(3):853-61.

59. Nagai T, Murai R, Matsui K, et al. Aripiprazole ameliorates phencyclidine-induced impairment of recognition memory 
through dopamine D1 and serotonin 5-HT1A receptors. Psychopharmacology (Berl). 2009;202(1-3):315-28.

60. Bruins Slot LA, Kleven MS, Newman-Tancredi A. Effects of novel antipsychotics with mixed $\mathrm{D}(2)$ antagonist/5-HT(1A) agonist properties on PCP-induced social interaction deficits in the rat. Neuropharmacology. 2005;49(7):996-1006.

61. Snigdha S, Neill JC. Improvement of phencyclidine-induced social behaviour deficits in rats: involvement of 5-HT1A receptors. Behav Brain Res. 2008;191(1):26-31.

62. Li Z, Ichikawa J, Dai J, et al. Aripiprazole, a novel antipsychotic drug, preferentially increases dopamine release in the prefrontal cortex and hippocampus in rat brain. Eur $\mathrm{J}$ Pharmacol. 2004:493(1-3):75-83.

63. Zocchi A, Fabbri D, Heidbreder CA. Aripiprazole increases dopamine but not noradrenaline and serotonin levels in the mouse prefrontal cortex. Neurosci Lett. 2005;387(3):157-61.

64. Assie MB, Ravailhe V, Faucillon V, et al. Contrasting contribution of 5-hydroxytryptamine $1 \mathrm{~A}$ receptor activation to neurochemical profile of novel antipsychotics: frontocortical dopamine and hippocampal serotonin release in rat brain. J Pharmacol Exp Ther. 2005;315(1):265-72.

65. Bortolozzi A, Diaz-Mataix L, Toth M, et al. In vivo actions of aripiprazole on serotonergic and dopaminergic systems in rodent brain. Psychopharmacology (Berl). 2007;191(3):745-58.

66. Tanahashi S, Yamamura S, Nakagawa M, et al. Dopamine D2 and serotonin 5-HT1A receptors mediate the actions of aripiprazole in mesocortical and mesoaccumbens transmission. Neuropharmacology. 2012;62(2):765-74.

67. Carli M, Calcagno E, Mainolfi P, et al. Effects of aripiprazole, olanzapine, and haloperidol in a model of cognitive deficit of schizophrenia in rats: relationship with glutamate release in the medial prefrontal cortex. Psychopharmacology (Berl). 2011; 214(3):639-52.

68. Carli M, Invernizzi RW. Serotoninergic and dopaminergic modulation of cortico-striatal circuit in executive and attention deficits induced by nMDA receptor hypofunction in the 5-choice serial reaction time task. Front Neural Circuits. 2014;8:58.

69. Bortolozzi A, Amargos-Bosch M, Adell A, et al. In vivo modulation of 5-hydroxytryptamine release in mouse prefrontal cortex by local 5-HT(2A) receptors: effect of antipsychotic drugs. Eur J Neurosci. 2003;18(5):1235-46.

70. Zhang JY, Kowal DM, Nawoschik SP, et al. Distinct functional profiles of aripiprazole and olanzapine at RNA edited human 5-HT2C receptor isoforms. Biochem Pharmacol. 2006;71(4): $521-9$.

71. Kohnomi S, Suemaru K, Kawasaki H, et al. Effect of aripiprazole on 5-HT2 receptor-mediated wet-dog shake responses and disruption of prepulse inhibition in rats. J Pharmacol Sci. 2008;106(4):645-50.

72. Nguyen CT, Rosen JA, Bota RG. Aripiprazole partial agonism at 5-HT2C: a comparison of weight gain associated with aripiprazole adjunctive to antidepressants with high versus low serotonergic activities. Prim Care Companion CNS Disord. 2012;14(5).

73. de Bartolomeis A, Avvisati L, Iasevoli F, et al. Intracellular pathways of antipsychotic combined therapies: implication for psychiatric disorders treatment. Eur J Pharmacol. 2013;718 (1-3):502-23.

74. Farde L, Nordstrom AL, Wiesel FA, et al. Positron emission tomographic analysis of central D1 and D2 dopamine receptor occupancy in patients treated with classical neuroleptics and clozapine. Relation to extrapyramidal side effects. Arch Gen Psychiatry. 1992;49(7):538-44.

75. Kapur S, Zipursky R, Jones C, et al. Relationship between dopamine $\mathrm{D}(2)$ occupancy, clinical response, and side effects: a double-blind PET study of first-episode schizophrenia. Am J Psychiatry. 2000;157(4):514-20.

76. Kapur S, Seeman P. Antipsychotic agents differ in how fast they come off the dopamine D2 receptors. Implications for atypical antipsychotic action. J Psychiatry Neurosci. 2000;25(2):161-6.

77. Kapur S, Zipursky R, Jones C, et al. A positron emission tomography study of quetiapine in schizophrenia: a preliminary finding of an antipsychotic effect with only transiently high dopamine D2 receptor occupancy. Arch Gen Psychiatry. 2000;57(6):553-9.

78. Mamo D, Graff A, Mizrahi R, et al. Differential effects of aripiprazole on $\mathrm{D}(2), 5-\mathrm{HT}(2)$, and 5-HT(1A) receptor occupancy in patients with schizophrenia: a triple tracer PET study. Am J Psychiatry. 2007;164(9):1411-7.

79. Kegeles LS, Slifstein M, Frankle WG, et al. Dose-occupancy study of striatal and extrastriatal dopamine D2 receptors by aripiprazole in schizophrenia with PET and [18F]fallypride. Neuropsychopharmacology. 2008;33(13):3111-25.

80. Grunder G, Landvogt C, Vernaleken I, et al. The striatal and extrastriatal D2/D3 receptor-binding profile of clozapine in patients with schizophrenia. Neuropsychopharmacology. 2006; 31(5):1027-35.

81. Tomasetti C, Dell'Aversano C, Iasevoli F, et al. Homer splice variants modulation within cortico-subcortical regions by dopamine D2 antagonists, a partial agonist, and an indirect agonist: implication for glutamatergic postsynaptic density in antipsychotics action. Neuroscience. 2007;150(1):144-58.

82. Takahata $\mathrm{K}$, Ito $\mathrm{H}$, Takano $\mathrm{H}$, et al. Striatal and extrastriatal dopamine $\mathrm{D}(2)$ receptor occupancy by the partial agonist antipsychotic drug aripiprazole in the human brain: a positron emission tomography study with [(1)(1)C]raclopride and [(1)(1)C]FLB457. Psychopharmacology (Berl). 2012;222(1): $165-72$.

83. Ito H, Takano H, Arakawa R, et al. Effects of dopamine D2 receptor partial agonist antipsychotic aripiprazole on dopamine synthesis in human brain measured by PET with L-[beta11C]DOPA. PLoS One. 2012;7(9):e46488.

84. Der-Ghazarian T, Charntikov S, Varela FA, et al. Effects of repeated and acute aripiprazole or haloperidol treatment on dopamine synthesis in the dorsal striatum of young rats: comparison to adult rats. J Neural Transm. 2010;117(5):573-83.

85. Han M, Huang XF, Deng C. Aripiprazole differentially affects mesolimbic and nigrostriatal dopaminergic transmission: implications for long-term drug efficacy and low extrapyramidal side-effects. Int J Neuropsychopharmacol. 2009;12(7):941-52.

86. Inoue A, Seto M, Sugita S, et al. Differential effects on D2 dopamine receptor and prolactin gene expression by haloperidol and aripiprazole in the rat pituitary. Brain Res Mol Brain Res. 1998;55(2):285-92.

87. De Berardis D, Fornaro M, Serroni N, et al. Treatment of antipsychotic-induced hyperprolactinemia: an update on the role of the dopaminergic receptors D2 partial agonist aripiprazole. Recent Pat Endocr Metab Immune Drug Discov. 2014;8(1):30-7.

88. Han M, Huang XF, du Bois TM, et al. The effects of antipsychotic drugs administration on 5-HT1A receptor expression in the limbic system of the rat brain. Neuroscience. 2009;164(4): 1754-63.

89. Han M, Deng C, Burne TH, et al. Short- and long-term effects of antipsychotic drug treatment on weight gain and $\mathrm{H} 1$ receptor expression. Psychoneuroendocrinology. 2008;33(5):569-80.

90. Han M, Newell K, Zavitsanou K, et al. Effects of antipsychotic medication on muscarinic M1 receptor mRNA expression in the rat brain. J Neurosci Res. 2008;86(2):457-64.

91. Peselmann N, Schmitt A, Gebicke-Haerter PJ, et al. Aripiprazole differentially regulates the expression of Gad67 and gamma- 
aminobutyric acid transporters in rat brain. Eur Arch Psychiatry Clin Neurosci. 2013;263(4):285-97.

92. Segnitz N, Ferbert T, Schmitt A, et al. Effects of chronic oral treatment with aripiprazole on the expression of nMDA receptor subunits and binding sites in rat brain. Psychopharmacology (Berl). 2011;217(1):127-42.

93. Segnitz N, Schmitt A, Gebicke-Harter PJ, et al. Differential expression of glutamate transporter genes after chronic oral treatment with aripiprazole in rats. Neurochem Int. 2009;55(7): 619-28.

94. Cheng MC, Liao DL, Hsiung CA, et al. Chronic treatment with aripiprazole induces differential gene expression in the rat frontal cortex. Int J Neuropsychopharmacol. 2008;11(2):207-16.

95. Lyford GL, Yamagata K, Kaufmann WE, et al. Arc, a growth factor and activity-regulated gene, encodes a novel cytoskeleton-associated protein that is enriched in neuronal dendrites. Neuron. 1995;14(2):433-45.

96. Waters S, Ponten H, Edling M, et al. The dopaminergic stabilizers pridopidine and ordopidine enhance cortico-striatal Arc gene expression. J Neural Transm. 2014;121(11):1337-47.

97. de Bartolomeis A, Iasevoli F. The Homer family and the signal transduction system at glutamatergic postsynaptic density: potential role in behavior and pharmacotherapy. Psychopharmacol Bull. 2003;37(3):51-83.

98. Iasevoli F, Tomasetti C, de Bartolomeis A. Scaffolding proteins of the post-synaptic density contribute to synaptic plasticity by regulating receptor localization and distribution: relevance for neuropsychiatric diseases. Neurochem Res. 2013;38(1):1-22.

99. Iasevoli F, Tomasetti C, Marmo F, et al. Divergent acute and chronic modulation of glutamatergic postsynaptic density genes expression by the antipsychotics haloperidol and sertindole. Psychopharmacology (Berl). 2010;212(3):329-44.

100. Iasevoli F, Fiore G, Cicale M, et al. Haloperidol induces higher Homer1a expression than risperidone, olanzapine and sulpiride in striatal sub-regions. Psychiatry Res. 2010;177(1-2):255-60.

101. Iasevoli F, Ambesi-Impiombato A, Fiore G, et al. Pattern of acute induction of Homerla gene is preserved after chronic treatment with first- and second-generation antipsychotics: effect of short-term drug discontinuation and comparison with Homer1a-interacting genes. J Psychopharmacol. 2011;25(7): 875-87.

102. Tomasetti C, Dell'Aversano C, Iasevoli F, et al. The acute and chronic effects of combined antipsychotic-mood stabilizing treatment on the expression of cortical and striatal postsynaptic density genes. Prog Neuropsychopharmacol Biol Psychiatry. 2011;35(1):184-97.

103. de Bartolomeis A, Marmo F, Buonaguro EF, et al. Imaging brain gene expression profiles by antipsychotics: region-specific action of amisulpride on postsynaptic density transcripts compared to haloperidol. Eur Neuropsychopharmacol. 2013;23(11): 1516-29.

104. Iasevoli F, Tomasetti C, Ambesi-Impiombato A, et al. Dopamine receptor subtypes contribution to Homer1a induction: insights into antipsychotic molecular action. Prog Neuropsychopharmacol Biol Psychiatry. 2009;33(5):813-21.

105. Iasevoli F, Polese D, Ambesi-Impiombato A, et al. Ketaminerelated expression of glutamatergic postsynaptic density genes: possible implications in psychosis. Neurosci Lett. 2007;416(1): $1-5$.

106. de Bartolomeis A, Sarappa C, Buonaguro EF, et al. Different effects of the nMDA receptor antagonists ketamine, MK-801, and memantine on postsynaptic density transcripts and their topography: role of Homer signaling, and implications for novel antipsychotic and pro-cognitive targets in psychosis. Prog Neuropsychopharmacol Biol Psychiatry. 2013;46:1-12.
107. Mei L, Xiong WC. Neuregulin 1 in neural development, synaptic plasticity and schizophrenia. Nat Rev Neurosci. 2008;9(6):437-52.

108. Stefansson H, Ophoff RA, Steinberg S, et al. Common variants conferring risk of schizophrenia. Nature. 2009;460(7256):744-7.

109. Yin DM, Chen YJ, Lu YS, et al. Reversal of behavioral deficits and synaptic dysfunction in mice overexpressing neuregulin 1 . Neuron. 2013;78(4):644-57.

110. Kwon OB, Paredes D, Gonzalez CM, et al. Neuregulin-1 regulates LTP at CA1 hippocampal synapses through activation of dopamine D4 receptors. Proc Natl Acad Sci USA. 2008;105(40):15587-92.

111. Deng C, Pan B, Hu CH, et al. Differential effects of short- and long-term antipsychotic treatment on the expression of neuregulin-1 and ErbB4 receptors in the rat brain. Psychiatry Res. 2015;225(3):347-54.

112. Ram R, Bromet EJ, Eaton WW, et al. The natural course of schizophrenia: a review of first-admission studies. Schizophr Bull. 1992;18(2):185-207.

113. Menezes NM, Arenovich T, Zipursky RB. A systematic review of longitudinal outcome studies of first-episode psychosis. Psychol Med. 2006;36(10):1349-62.

114. Suzuki T, Uchida H, Takeuchi $\mathrm{H}$, et al. A review on schizophrenia and relapse-a quest for user-friendly psychopharmacotherapy. Hum Psychopharmacol. 2014;29(5):414-26.

115. Johnson DA. Historical perspective on antipsychotic long-acting injections. Br J Psychiatry Suppl. 2009;52:S7-12.

116. Kirson NY, Weiden PJ, Yermakov S, et al. Efficacy and effectiveness of depot versus oral antipsychotics in schizophrenia: synthesizing results across different research designs. J Clin Psychiatry. 2013;74(6):568-75.

117. Kishimoto T, Robenzadeh A, Leucht $\mathrm{C}$, et al. Long-acting injectable vs oral antipsychotics for relapse prevention in schizophrenia: a meta-analysis of randomized trials. Schizophr Bull. 2014;40(1):192-213.

118. Rauch AS, Fleischhacker WW. Long-acting injectable formulations of new-generation antipsychotics: a review from a clinical perspective. CNS Drugs. 2013;27(8):637-52.

119. Bressan RA, Jones HM, Ell PJ, et al. Dopamine D(2) receptor blockade in schizophrenia. Am J Psychiatry. 2001;158(6):971-2.

120. Turrone P, Remington G, Kapur S, et al. Differential effects of within-day continuous vs. transient dopamine D2 receptor occupancy in the development of vacuous chewing movements (VCMs) in rats. Neuropsychopharmacology. 2003;28(8):1433-9.

121. Turrone P, Remington G, Kapur S, et al. Continuous but not intermittent olanzapine infusion induces vacuous chewing movements in rats. Biol Psychiatry. 2005;57(4):406-11.

122. Samaha AN, Reckless GE, Seeman P, et al. Less is more: antipsychotic drug effects are greater with transient rather than continuous delivery. Biol Psychiatry. 2008;64(2):145-52.

123. Uchida H, Suzuki T. Dose and dosing frequency of long-acting injectable antipsychotics: a systematic review of PET and SPECT data and clinical implications. J Clin Psychopharmacol. 2014;34(6):728-35.

124. Rosenheck RA, Krystal JH, Lew R, et al. Long-acting risperidone and oral antipsychotics in unstable schizophrenia. N Engl J Med. 2011;364(9):842-51.

125. Leucht C, Heres S, Kane JM, et al. Oral versus depot antipsychotic drugs for schizophrenia-a critical systematic review and meta-analysis of randomised long-term trials. Schizophr Res. 2011;127(1-3):83-92.

126. Zhornitsky S, Stip E. Oral versus long-acting injectable antipsychotics in the treatment of schizophrenia and special populations at risk for treatment nonadherence: a systematic review. Schizophr Res Treat. 2012;2012:407171. 
127. Kane JM, Sanchez R, Perry PP, et al. Aripiprazole intramuscular depot as maintenance treatment in patients with schizophrenia: a 52-week, multicenter, randomized, double-blind, placebo-controlled study. J Clin Psychiatry. 2012;73(5):617-24.

128. Fleischhacker WW, Sanchez R, Perry PP, et al. Aripiprazole once-monthly for treatment of schizophrenia: double-blind, randomised, non-inferiority study. Br J Psychiatry. 2014;205(2): $135-44$.

129. Potkin SG, Raoufinia A, Mallikaarjun S, et al. Safety and tolerability of once monthly aripiprazole treatment initiation in adults with schizophrenia stabilized on selected atypical oral antipsychotics other than aripiprazole. Curr Med Res Opin. 2013;29(10): 1241-51.

130. Inoue A, Miki S, Seto M, et al. Aripiprazole, a novel antipsychotic drug, inhibits quinpirole-evoked GTPase activity but does not up-regulate dopamine D2 receptor following repeated treatment in the rat striatum. Eur J Pharmacol. 1997;321(1):105-11.

131. Jordan S, Koprivica V, Dunn R, et al. In vivo effects of aripiprazole on cortical and striatal dopaminergic and serotonergic function. Eur J Pharmacol. 2004;483(1):45-53.

132. Park SW, Phuong VT, Lee $\mathrm{CH}$, et al. Effects of antipsychotic drugs on BDNF, GSK-3beta, and beta-catenin expression in rats subjected to immobilization stress. Neurosci Res. 2011;71(4):335-40.

133. Luoni A, Fumagalli F, Racagni G, et al. Repeated aripiprazole treatment regulates Bdnf, Arc and Npas4 expression under basal condition as well as after an acute swim stress in the rat brain. Pharmacol Res. 2014;80:1-8.

134. Tadokoro S, Okamura N, Sekine Y, et al. Chronic treatment with aripiprazole prevents development of dopamine supersensitivity and potentially supersensitivity psychosis. Schizophr Bull. 2012;38(5):1012-20.

135. Chouinard G, Jones BD, Annable L. Neuroleptic-induced supersensitivity psychosis. Am J Psychiatry. 1978;135(11):1409-10.

136. Fallon P, Dursun SM. A naturalistic controlled study of relapsing schizophrenic patients with tardive dyskinesia and supersensitivity psychosis. J Psychopharmacol. 2011;25(6):755-62.

137. Seeman P, Schwarz J, Chen JF, et al. Psychosis pathways converge via D2high dopamine receptors. Synapse. 2006;60(4):319-46.

138. Seeman MV, Seeman P. Is schizophrenia a dopamine supersensitivity psychotic reaction? Prog Neuropsychopharmacol Biol Psychiatry. 2014;48:155-60.

139. Fallon P, Dursun S, Deakin B. Drug-induced supersensitivity psychosis revisited: characteristics of relapse in treatment-compliant patients. Ther Adv Psychopharmacol. 2012;2(1):13-22.

140. Feltenstein MW, Altar CA, See RE. Aripiprazole blocks reinstatement of cocaine seeking in an animal model of relapse. Biol Psychiatry. 2007;61(5):582-90.

141. Thomsen M, Fink-Jensen A, Woldbye DP, et al. Effects of acute and chronic aripiprazole treatment on choice between cocaine selfadministration and food under a concurrent schedule of reinforcement in rats. Psychopharmacology (Berl). 2008;201(1):43-53.

142. Kinon BJ, Chen L, Ascher-Svanum H, et al. Early response to antipsychotic drug therapy as a clinical marker of subsequent response in the treatment of schizophrenia. Neuropsychopharmacology. 2010;35(2):581-90.

143. Sinclair D, Adams CE. Treatment resistant schizophrenia: a comprehensive survey of randomised controlled trials. BMC Psychiatry. 2014;14:253.

144. Bilic P, Jukic V, Vilibic $M$, et al. Treatment-resistant schizophrenia and DAT and SERT polymorphisms. Gene. 2014;543(1):125-32.

145. Demjaha A, Murray RM, McGuire PK, et al. Dopamine synthesis capacity in patients with treatment-resistant schizophrenia. Am J Psychiatry. 2012;169(11):1203-10.

146. Quarantelli M, Palladino O, Prinster A, et al. Patients with poor response to antipsychotics have a more severe pattern of frontal atrophy: a voxel-based morphometry study of treatment resistance in schizophrenia. Biomed Res Int. 2014;2014:325052.

147. Teo C, Zai C, Borlido C, et al. Analysis of treatment-resistant schizophrenia and 384 markers from candidate genes. Pharmacogenet Genom. 2012;22(11):807-11.

148. Samaha AN, Seeman P, Stewart J, et al. "Breakthrough" dopamine supersensitivity during ongoing antipsychotic treatment leads to treatment failure over time. J Neurosci. 2007;27(11):2979-86.

149. Gao J, Qin R, Li M. Repeated administration of aripiprazole produces a sensitization effect in the suppression of avoidance responding and phencyclidine-induced hyperlocomotion and increases D2 receptor-mediated behavioral function. J Psychopharmacol. 2015;29(4):390-400.

150. Tamminga CA. Partial dopamine agonists in the treatment of psychosis. J Neural Transm. 2002;109(3):411-20.

151. Tamminga CA, Carlsson A. Partial dopamine agonists and dopaminergic stabilizers, in the treatment of psychosis. Curr Drug Targets CNS Neurol Disord. 2002;1(2):141-7.

152. Mottola DM, Brewster WK, Cook LL, et al. Dihydrexidine, a novel full efficacy D1 dopamine receptor agonist. J Pharmacol Exp Ther. 1992;262(1):383-93.

153. Mottola DM, Kilts JD, Lewis MM, et al. Functional selectivity of dopamine receptor agonists. I. Selective activation of postsynaptic dopamine D2 receptors linked to adenylate cyclase. J Pharmacol Exp Ther. 2002;301(3):1166-78.

154. Kilts JD, Connery HS, Arrington EG, et al. Functional selectivity of dopamine receptor agonists. II. Actions of dihydrexidine in D2L receptor-transfected MN9D cells and pituitary lactotrophs. J Pharmacol Exp Ther. 2002;301(3):1179-89.

155. Isacson R, Kull B, Wahlestedt C, et al. A 68930 and dihydrexidine inhibit locomotor activity and d-amphetamine-induced hyperactivity in rats: a role of inhibitory dopamine $D(1 / 5)$ receptors in the prefrontal cortex? Neuroscience. 2004;124(1): 33-42.

156. Ralph-Williams RJ, Lehmann-Masten V, Geyer MA. Dopamine D1 rather than D2 receptor agonists disrupt prepulse inhibition of startle in mice. Neuropsychopharmacology. 2003;28(1):108-18.

157. Mu Q, Johnson K, Morgan PS, et al. A single $20 \mathrm{mg}$ dose of the full D1 dopamine agonist dihydrexidine (DAR-0100) increases prefrontal perfusion in schizophrenia. Schizophr Res. 2007; 94(1-3):332-41.

158. George MS, Molnar CE, Grenesko EL, et al. A single $20 \mathrm{mg}$ dose of dihydrexidine (DAR-0100), a full dopamine D1 agonist, is safe and tolerated in patients with schizophrenia. Schizophr Res. 2007;93(1-3):42-50.

159. Rosell DR, Zaluda LC, McClure MM, et al. Effects of the D1 dopamine receptor agonist dihydrexidine (DAR-0100A) on working memory in schizotypal personality disorder. Neuropsychopharmacology. 2015;40(2):446-53.

160. Zhang X, Nakata Y, Kikuchi T, et al. Interactions of 7-[3-(4[2,3-dimethylphenyl]piperazinyl)-propoxy]-2(1H)-quinolinone binding in rat striatum: effects of lesions. Pharm Res. 1990; $7(3): 280-2$.

161. Benkert O, Muller-Siecheneder F, Wetzel H. Dopamine agonists in schizophrenia: a review. Eur Neuropsychopharmacol. 1995; 5(Suppl):43-53.

162. Newman-Tancredi A, Cussac D, Audinot V, et al. Differential actions of antiparkinson agents at multiple classes of monoaminergic receptor. II. Agonist and antagonist properties at subtypes of dopamine D(2)-like receptor and alpha(1)/alpha(2)adrenoceptor. J Pharmacol Exp Ther. 2002;303(2):805-14.

163. Zorad S, Golda V, Fickova M, et al. Terguride treatment attenuated prolactin release and enhanced insulin receptor affinity and GLUT 4 content in obese spontaneously hypertensive female, but not male rats. Ann $\mathrm{N}$ Y Acad Sci. 2002;967:490-9. 
164. Golda V, Fickova M, Pinterova L, et al. Terguride attenuates prolactin levels and ameliorates insulin sensitivity and insulin binding in obese spontaneously hypertensive rats. Physiol Res. 2001;50(2): 175-82.

165. Orsini C, Koob GF, Pulvirenti L. Dopamine partial agonist reverses amphetamine withdrawal in rats. Neuropsychopharmacology. 2001;25(5):789-92.

166. Pulvirenti L, Koob GF. Dopamine receptor agonists, partial agonists and psychostimulant addiction. Trends Pharmacol Sci. 1994;15(10):374-9.

167. Pulvirenti L, Balducci C, Piercy M, et al. Characterization of the effects of the partial dopamine agonist terguride on cocaine selfadministration in the rat. J Pharmacol Exp Ther. 1998;286(3): 1231-8.

168. Jordan S, Johnson JL, Regardie K, et al. Dopamine D2 receptor partial agonists display differential or contrasting characteristics in membrane and cell-based assays of dopamine D2 receptor signaling. Prog Neuropsychopharmacol Biol Psychiatry. 2007;31(2):348-56

169. Nakai S, Hirose T, Mori T, et al. The effect of aripiprazole on prepulse inhibition of the startle response in normal and hyperdopaminergic states in rats. Int J Neurosci. 2008;118(1): 39-57.

170. Jantschak F, Brosda J, Franke RT, et al. Pharmacological profile of 2-bromoterguride at human dopamine D2, porcine serotonin 5-hydroxytryptamine $2 \mathrm{~A}$, and alpha2C-adrenergic receptors, and its antipsychotic-like effects in rats. J Pharmacol Exp Ther. 2013;347(1):57-68.

171. Hinzen D, Hornykiewicz O, Kobinger W, et al. The dopamine autoreceptor agonist B-HT 920 stimulates denervated postsynaptic brain dopamine receptors in rodent and primate models of Parkinson's disease: a novel approach to treatment. Eur J Pharmacol. 1986;131(1):75-86.

172. Ohmori T, Koyama T, Inoue T, et al. B-HT 920, a dopamine D2 agonist, in the treatment of negative symptoms of chronic schizophrenia. Biol Psychiatry. 1993;33(10):687-93.

173. Bartoszyk GD, Harting J, Minck KO. Roxindole: psychopharmacological profile of a dopamine D2 autoreceptor agonist. J Pharmacol Exp Ther. 1996;276(1):41-8.

174. Wetzel H, Hillert A, Grunder G, et al. Roxindole, a dopamine autoreceptor agonist, in the treatment of positive and negative schizophrenic symptoms. Am J Psychiatry. 1994;151(10): 1499-502.

175. Coward DM, Dixon AK, Urwyler S, et al. Partial dopamineagonistic and atypical neuroleptic properties of the amino-ergolines SDZ 208-911 and SDZ 208-912. J Pharmacol Exp Ther. 1990;252(1):279-85.

176. Dyhring T, Nielsen EO, Sonesson C, et al. The dopaminergic stabilizers pridopidine (ACR16) and (-)-OSU6162 display dopamine $\mathrm{D}(2)$ receptor antagonism and fast receptor dissociation properties. Eur J Pharmacol. 2010;628(1-3):19-26.

177. Tadori Y, Kitagawa H, Forbes RA, et al. Differences in agonist/ antagonist properties at human dopamine $\mathrm{D}(2)$ receptors between aripiprazole, bifeprunox and SDZ 208-912. Eur J Pharmacol. 2007;574(2-3):103-11.

178. Wustrow D, Belliotti T, Glase S, et al. Aminopyrimidines with high affinity for both serotonin and dopamine receptors. J Med Chem. 1998;41(5):760-71.

179. Akunne HC, Zoski KT, Davis MD, et al. PD 158771, a potential antipsychotic agent with $\mathrm{D}(2) / \mathrm{D}(3)$ partial agonist and 5-HT(1A) agonist actions. I. Neurochemical effects. Neuropharmacology. 2000;39(7):1197-210.

180. Corbin AE, Meltzer LT, Ninteman FW, et al. PD 158771, a potential antipsychotic agent with D2/D3 partial agonist and 5-HT(1A) agonist actions. II. Preclinical behavioral effects. Neuropharmacology. 2000;39(7):1211-21.
181. Rugsley TA, Davis MD, Akunne HC, et al. CI-1007, a dopamine partial agonist and potential antipsychotic agent. I. Neurochemical effects. J Pharmacol Exp Ther. 1995;274(2):898-911.

182. Meltzer LT, Christoffersen CL, Corbin AE, et al. CI-1007, a dopamine partial agonist and potential antipsychotic agent. II. Neurophysiological and behavioral effects. J Pharmacol Exp Ther. 1995;274(2):912-20.

183. Feng MR, Siersma PR, Strenkoski CA, et al. Sensitive high-performance liquid chromatographic method for a dopamine receptor agonist, CI-1007, and its metabolite PD 147693 in monkey plasma. J Chromatogr B Biomed Appl. 1995;665(1):193-9.

184. Iyer RN, Davis MD, Juneau PL, et al. Brain extracellular levels of the putative antipsychotic CI-1007 and its effects on striatal and nucleus accumbens dopamine overflow in the awake rat. J Pharm Pharmacol. 1998;50(10):1147-53.

185. Sramek JJ, Eldon MA, Posvar E, et al. Initial safety, tolerability pharmacodynamics, and pharmacokinetics of CI-1007 in patients with schizophrenia. Psychopharmacol Bull. 1998;34(1): 93-9.

186. Heinrich JN, Brennan J, Lai MH, et al. Aplindore (DAB-452), a high affinity selective dopamine D2 receptor partial agonist. Eur J Pharmacol. 2006;552(1-3):36-45.

187. Klivenyi P, Vecsei L. Novel therapeutic strategies in Parkinson's disease. Eur J Clin Pharmacol. 2010;66(2):119-25.

188. Jackson MJ, Andree TH, Hansard M, et al. The dopamine D(2) receptor partial agonist aplindore improves motor deficits in MPTP-treated common marmosets alone and combined with Ldopa. J Neural Transm. 2010;117(1):55-67.

189. Wolf W. DU-127090 Solvay/H Lundbeck. Curr Opin Investig Drugs. 2003;4(1):72-6.

190. Bardin L, Auclair A, Kleven MS, et al. Pharmacological profiles in rats of novel antipsychotics with combined dopamine D2/serotonin 5-HT1A activity: comparison with typical and atypical conventional antipsychotics. Behav Pharmacol. 2007;18(2):103-18.

191. Auclair AL, Galinier A, Besnard J, et al. Putative antipsychotics with pronounced agonism at serotonin 5-HT1A and partial agonist activity at dopamine D2 receptors disrupt basal PPI of the startle reflex in rats. Psychopharmacology (Berl). 2007;193(1):45-54.

192. De Santis M, Pan B, Lian J, et al. Different effects of bifeprunox, aripiprazole, and haloperidol on body weight gain, food and water intake, and locomotor activity in rats. Pharmacol Biochem Behav. 2014;124:167-73.

193. Casey DE, Sands EE, Heisterberg J, et al. Efficacy and safety of bifeprunox in patients with an acute exacerbation of schizophrenia: results from a randomized, double-blind, placebo-controlled, multicenter, dose-finding study. Psychopharmacology (Berl). 2008;200(3):317-31.

194. Assie MB, Carilla-Durand E, Bardin L, et al. The antipsychotics clozapine and olanzapine increase plasma glucose and corticosterone levels in rats: comparison with aripiprazole, ziprasidone, bifeprunox and F15063. Eur J Pharmacol. 2008;592(1-3): $160-6$.

195. Citrome L. Cariprazine in schizophrenia: clinical efficacy, tolerability, and place in therapy. Adv Ther. 2013;30(2):114-26.

196. Newman-Tancredi A, Kleven MS. Comparative pharmacology of antipsychotics possessing combined dopamine D2 and serotonin 5-HT1A receptor properties. Psychopharmacology (Berl). 2011;216(4):451-73.

197. Veselinovic T, Paulzen M, Grunder G. Cariprazine, a new, orally active dopamine D2/3 receptor partial agonist for the treatment of schizophrenia, bipolar mania and depression. Expert Rev Neurother. 2013;13(11):1141-59.

198. Altinbas K, Guloksuz S, Oral ET. Clinical potential of cariprazine in the treatment of acute mania. Psychiatr Danub. 2013;25(3):207-13. 
199. Pettersson F, Ponten H, Waters N, et al. Synthesis and evaluation of a set of 4-phenylpiperidines and 4-phenylpiperazines as D2 receptor ligands and the discovery of the dopaminergic stabilizer 4-[3-(methylsulfonyl)phenyl]-1-propylpiperidine (huntexil, pridopidine, ACR16). J Med Chem. 2010;53(6):2510-20.

200. Natesan S, Svensson KA, Reckless GE, et al. The dopamine stabilizers (S)-(-)-(3-methanesulfonyl-phenyl)-1-propyl-piperidine [(-)-OSU6162] and 4-(3-methanesulfonylphenyl)-1-propylpiperidine (ACR16) show high in vivo D2 receptor occupancy, antipsychotic-like efficacy, and low potential for motor side effects in the rat. J Pharmacol Exp Ther. 2006;318(2):810-8.

201. Rung JP, Rung E, Helgeson L, et al. Effects of (-)-OSU6162 and ACR16 on motor activity in rats, indicating a unique mechanism of dopaminergic stabilization. J Neural Transm. 2008;115(6):899-908.

202. Ponten H, Kullingsjo J, Lagerkvist S, et al. In vivo pharmacology of the dopaminergic stabilizer pridopidine. Eur J Pharmacol. 2010;644(1-3):88-95.

203. Kara E, Lin H, Svensson K, et al. Analysis of the actions of the novel dopamine receptor-directed compounds (S)-OSU6162 and ACR16 at the D2 dopamine receptor. $\mathrm{Br} \mathrm{J}$ Pharmacol. 2010;161(6):1343-50.

204. Maeda K, Sugino H, Akazawa H, et al. Brexpiprazole I: in vitro and in vivo characterization of a novel serotonin-dopamine activity modulator. J Pharmacol Exp Ther. 2914;350(3):589-604.

205. Maeda K, Lerdrup L, Sugino H, et al. Brexpiprazole II: antipsychotic-like profile and pro-cognitive effects of a novel serotonin-dopamine activity modulator. J Pharmacol Exp Ther. 2014;350(3):605-14.
206. Yoshimi N, Fujita Y, Ohgi Y, et al. Effects of brexpiprazole, a novel serotonin-dopamine activity modulator, on phencyclidine-induced cognitive deficits in mice: a role for serotonin 5-HT receptors. Pharmacol Biochem Behav. 2014;124C:245-9.

207. Kane JM, Skuban A, Ouyang J, et al. A multicenter, randomized, double-blind, controlled phase 3 trial of fixed-dose brexpiprazole for the treatment of adults with acute schizophrenia. Schizophr Res. 2015;164(1-3):127-35.

208. Aihara K, Shimada J, Miwa T, et al. The novel antipsychotic aripiprazole is a partial agonist at short and long isoforms of D2 receptors linked to the regulation of adenylyl cyclase activity and prolactin release. Brain Res. 2004;1003(1-2):9-17.

209. Tadori Y, Miwa T, Tottori K, et al. Aripiprazole's low intrinsic activities at human dopamine D2L and D2S receptors render it a unique antipsychotic. Eur J Pharmacol. 2005;515(1-3):10-9.

210. Bruins Slot LA, De Vries L, Newman-Tancredi A, et al. Differential profile of antipsychotics at serotonin 5-HT1A and dopamine D2S receptors coupled to extracellular signal-regulated kinase. Eur J Pharmacol. 2006;534(1-3):63-70.

211. Tadori Y, Forbes RA, McQuade RD, et al. Characterization of aripiprazole partial agonist activity at human dopamine D3 receptors. Eur J Pharmacol. 2008;597(1-3):27-33.

212. Newman-Tancredi A, Heusler P, Martel JC, et al. Agonist and antagonist properties of antipsychotics at human dopamine D4.4 receptors: G-protein activation and $\mathrm{K}^{+}$channel modulation in transfected cells. Int J Neuropsychopharmacol. 2008;11(3): 293-307. 